\title{
Global warming and cooling: friend and foe to mankind.
}

\author{
Sokeland WP* \\ Retired Heat Transfer Expert, Spacecraft and Turbine Engines, Oakland City, Indiana 47660, USA
}

\begin{abstract}
The Supernova and Nova Impact Theory, SNIT, proposes correlation between the right ascension locations of supernova remnants at the time of impact with respect to locations of red sand deposits and major oil fields indicating that the sand and oil fields are scars of the impact of the debris stream on our planet. The supernovas aiding the melt of the Wisconsin Glaciations ice caps also produce deep hydrocarbon deposits in the mantle forming many of the world's oil producing areas. A Specific mega event forms the Fertile Crescent and is correlated with an exit crater of an interstellar meteor that penetrates and exits the earth's mantle while forming the mud volcanic basin of the Black Sea. The Monogem Ring Supernova causes the beginning of the Wisconsin Ice Age by placing iron deposits in the eastern Pacific Ocean via its western terminus locations and the eastern terminus locations are suggested by high quality iron ore and manganese deposits on land in Eurasia, Africa, and the Cook Islands. SN 1006's deflected north western termini begins in the Greenland region and moves to the southeast to cause death via hotspots during 2014-2016 in Kazakhstan, India, and Pakistan. Grouped lower Alaskan average temperatures in the winter of $\mathbf{2 0 1 6}$ are an indicator of the end of the drought in California. The impacts of supernovas 1054 and $\mathbf{1 0 0 6}$ are marked by an out of season tornado outbreak in November 2005 and the record tornado outbreak in April 2011, respectively.
\end{abstract}

Keywords: Warming, global, supernova, nova, tornado, ice, crater, meteor.

\section{Introduction}

Supernova and Nova Impact Theory, SNIT, has discussed the impact of debris streams with regard to lose of life and heating concerns for our planet. The input of energy of the SNIT has warmed the planet by adding additional energy from supernova and nova debris streams due to exothermic chemical combustion of light incoming particles in our atmosphere. The chemical reactions adding energy to earth's atmosphere produce greenhouse gases from the light atomic mass particles of the incoming exploding star's atmosphere, hydrogen, carbon, and nitrogen. An obvious result of additional incoming energy is the melting of ice near the poles of our planet and carbon dioxide, $\mathrm{CO}_{2}$, production. The polar ice areas that are most visible as melt areas are sea ice. Recent and specific areas of incoming energy melting ice have been discussed and death has occurred in Asia and specifically India. If the incoming energy causes conditions detrimental to mankind, global warming becomes an enemy to mankind. In like manor, the lack of incoming energy from supernova and nova debris streams causes cold conditions like the Little Ice Age in the northern hemisphere that put extreme stress on humanity and the warming ending the Little Ice Age period was from the debris streams of Nova WZ Sagittae and other novas. This global warming became a boon to mankind.

The results of exploding star, debris stream impacts generally produce heating first and cooling next. Cooling due to supernova debris streams occurs after the carbon particle's heating when iron particles from the explosion enter the earth's biosphere. Everyone agrees that an excessive amount of iron added to the planet's bodies of water will make available food for algae blooms that could devour extreme amounts of $\mathrm{CO}_{2}$ and reduce greenhouse heating therefore, cooling the planet. It is suggested that a $\mathrm{CO}_{2}$ gradient has existed that causes extreme cooling for half the planet due to depletion of $\mathrm{CO}_{2}$ at the onset of the last glaciations of the Wisconsin Ice Age.

\section{Creation of Our Last Ice Age}

The phenomena proposed by SNIT offer to change many accepted theories including changes in world climate. The extreme cases are the beginning and ending of planetary glaciations or ice ages that occur infrequently as can be seen in Figure 1. The yellow areas are warm periods and the blue areas are cold periods in Figure 1.

The beginning of the Wisconsin Glaciations was near 110,000 years before present, YBP. Temperature and $\mathrm{CO}_{2}$ concentration was increasing due to the supernova strike of the Monogem Ring supernova to a maximum indicated by the red circle in Figure 1 [2,3]. The Monogem Ring supernova is associated with the J0659+1414 (B0656+14) Pulsar of age 110,000 YBP and 939 light-years from earth. This supernova is the third closest to our planet in this study and caused extreme changes in our climate via global cooling. The right ascension for the Monogem Ring supernova is 7.5 hours. The calculation for the eastern terminus location at the time of impact cannot be accurately determined because of the regression time of 110,000 YBP is beyond the age range for the value of modified right ascension accuracy.

The logic answering how the Monogem Ring supernova caused the Wisconsin Glaciations requires knowledge of the composition of a star before explosion. Stellar composition is 
best represented by the composition of our solar wind shown in Figure 2. Hydrogen and helium are not shown in Figure 2, but the other light gases that burn and cause global warming including carbon, $\mathrm{C}$, and nitrogen, $\mathrm{N}$, are elements of low atomic mass units, amu, and are shown to the left in Figure 2. The light elements arrive near the beginning of the debris stream and cause heating or global warming. The heavier element, iron, arrives after the heating phase and causes cooling by feeding the algae that absorbs $\mathrm{CO}_{2}$ and produces oxygen. A major clue is that iron, $\mathrm{Fe}$, and manganese, $\mathrm{Mn}$, are approximately of the same atomic mass indicated by the black oval in Figure 2 and will be deposited at the same longitudes at the western and eastern termini locations of the Monogem Ring supernova.

The location of the largest deposit of high quality iron ore in Ukraine is shown in Figure 3 by the black area.

There is a counterpart to the Eurasian iron deposit that emphasizes the magnetic bottle effect on the Monogem Ring supernova's eastern termini in Zambia, Africa shown in Figure 4. The location in Figure 4 for the iron ore deposit is approximately 30 degrees east longitude. Both iron ore locations of extraordinary purity support the ideas proposed by SNIT through the concentrated density of the incoming iron debris at the north and south eastern termini as the mechanism that accomplished both iron deposits on earth's surface.
The selection of the Monogem Ring Supernova comes from the age of the pulsar associated with the supernova remnant and the time of decreasing $\mathrm{CO}_{2}$ that began the Wisconsin Glaciation shown by a red circle in Figure 1. Since the age of the supernova remnant is hundreds of thousands of years, the correction in the impact time calculation due to distance is negligible.

The maximum glacial deposit for the northern hemisphere during the Wisconsin Glaciations is shown as the black areas in Figure 5. The orientation of the ice for the Wisconsin Glaciations is eschewed toward one 180 degree longitudinal sector as shown in Figure 5. The seeding 180 degree arc for the incoming debris stream from the Monogem Ring supernova is to the left and below the white line in Figure 5 and exists from the western terminus in the Pacific Ocean across North America to the eastern terminus at the land locations of the iron deposits in the eastern hemisphere, Africa and Ukraine, which explains the majority of the ice being in North America and northwestern Eurasia. Since the feeding area for the alga bloom due to iron deposits occurred in the east Pacific and Atlantic Oceans plus the Mediterranean Sea, the region of minimum $\mathrm{CO}_{2}$ concentration produced a non-symmetric arctic ice cap.

The question as to how the western termini were located in the Pacific Ocean is answered by the largest manganese deposit on our planet at the Cook Islands. The Cook Island deposit of

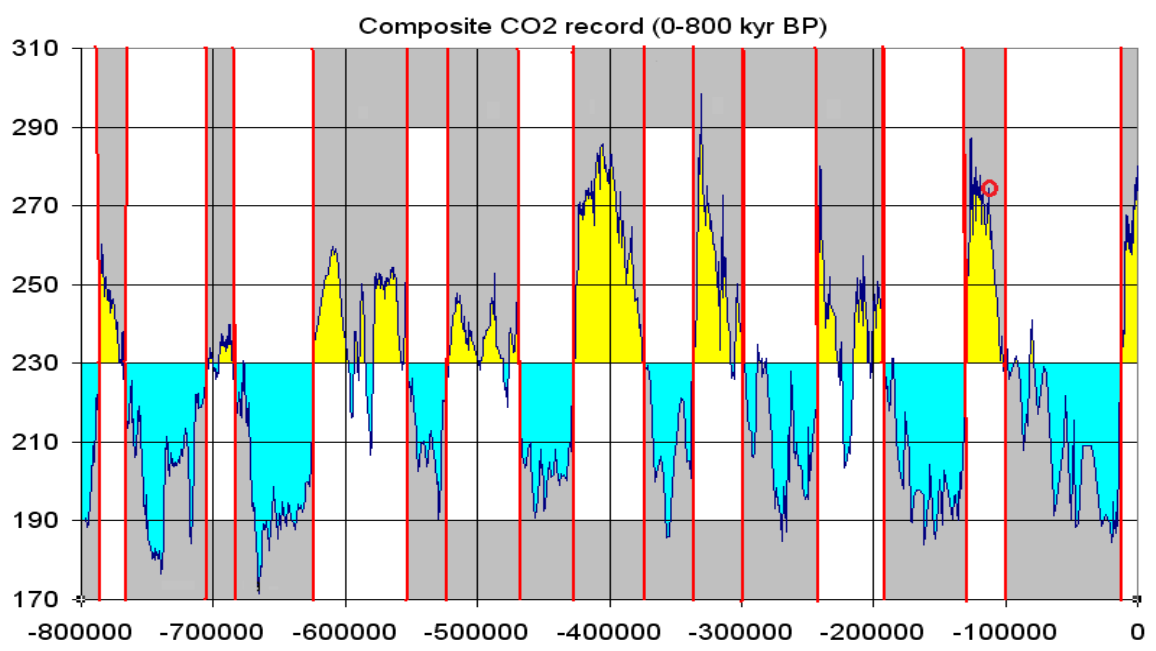

Figure 1. Greenland Ice Core $\mathrm{CO}_{2}$ Record [1].

Solar Wind Elements/Isotopes Observed by CELIAS MTOF

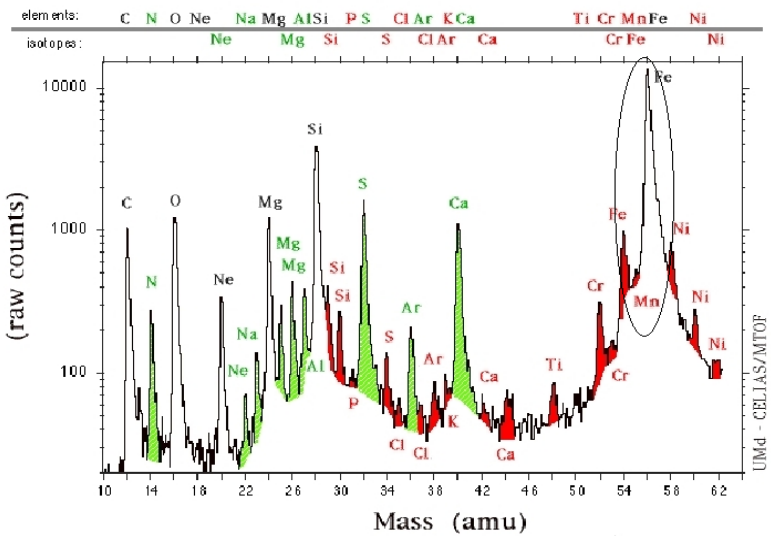

Figure 2. Solar Wind Composition [4]. 


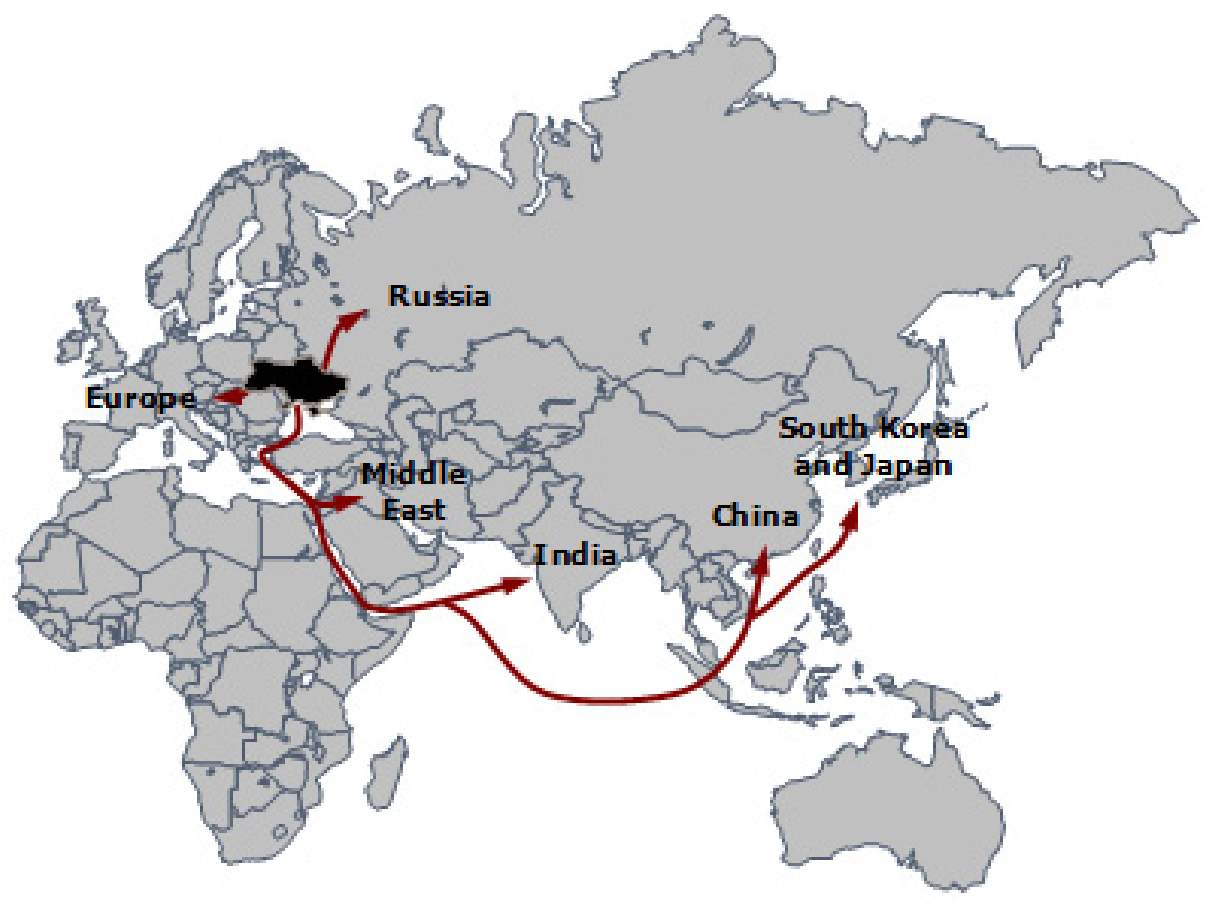

Figure 3. Ukraine Iron Ore Deposit [5].

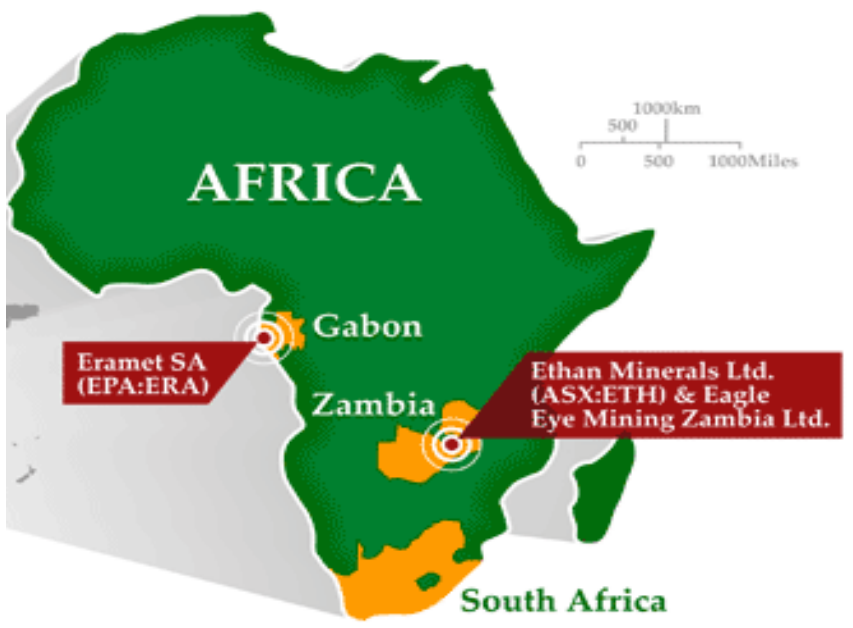

Figure 4. High Quality Iron Ore Deposit Africa [6].

manganese nodules appear to correlate with the iron deposits of the Monogem Ring Supernova as the south western terminus location and the largest land deposit of manganese in Northern Cape Province, South Africa locates the south eastern terminus. Both manganese deposits are near 20 degrees south latitude and separated by 180 degrees longitude (Figure 6).

The red circles in Figure 6 represent the high purity iron deposits on land. The black circles represent the high purity manganese deposits. The atomic mass of iron and manganese are near the same value indicating both deposits would be at matching longitudinal locations. The green circles represent a missing manganese deposit near Alaska and missing iron deposits of the western termini. The missing manganese deposit may be undiscovered at his time. The missing iron deposits at both green circles were devoured by the algae bloom that imitated the Wisconsin Glaciations 110,000 YBP. The fact that the Monogem Ring supernova is the third closest supernova implies higher particle densities than normal existing between western and eastern termini and the exploding star had a higher than normal amount of manganese and iron in its total mass.

\section{Destruction of Last Ice Age}

Carbon dioxide, $\mathrm{CO}_{2}$, studies in ice core data indicate the Wisconsin Glaciations existed for nearly 80,000 years, see Figure 1, and began to retreat due to warmer conditions at a time noted as the glacial maximum [9]. The following statement produces a critical data point for SNIT. "Climatically, the initial retreat from the glacial maximum was accompanied in Eastern Arabia by a period of extreme aridity from c.17,000 -11,000 BP." [10,11]. The statement not only gives the approximate time, it also gives the location for the extreme melting as the eastern hemisphere near Eastern Arabia. The author has no idea as to how much research occurred to produce this finding, but it is an amazing data point for SNIT. The time of 11,000 YBP was the end of the extreme aridity implying a large amount of moisture was forced into the atmosphere at or near the prescribed location. 


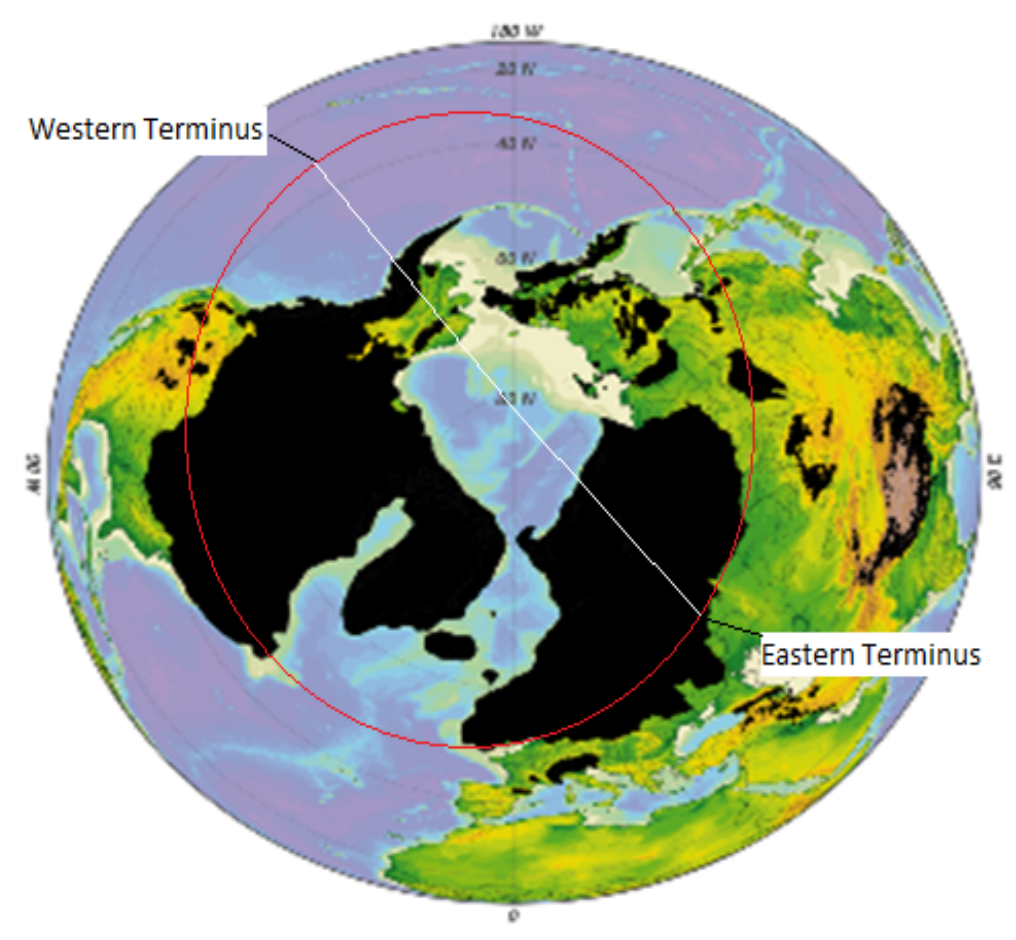

Figure 5. Wisconsin Glacial Maximum versus Iron Seeding Semicircle [7].

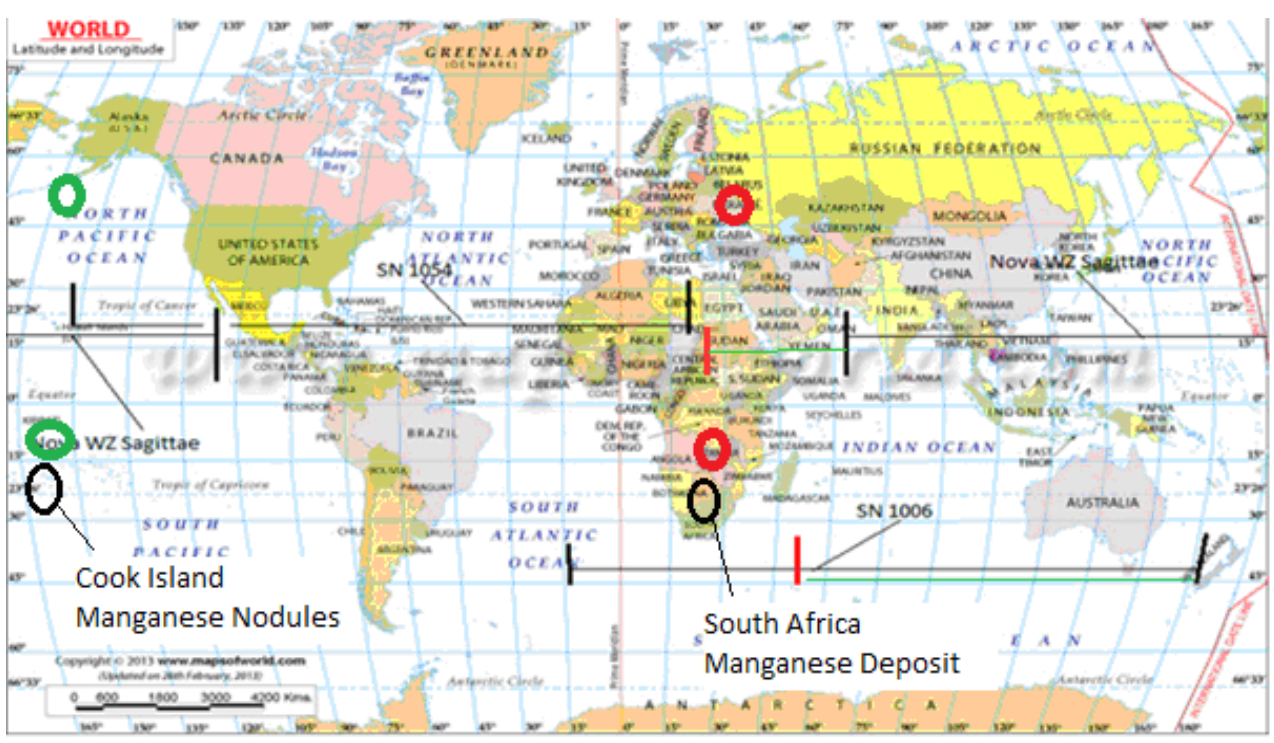

Figure 6. Iron and Manganese Deposits Monogem Ring Supernova [8].

Periods of excessive ice melt causing sea level rise resulting from supernova debris impacts melting the Wisconsin Glaciations ice are noted in Table 1 . The period of extreme aridity ended during the $1 \mathrm{~B}$ melt water phase, MWP. It is safe to state that an extreme amount of moisture was added to the atmosphere during MWP1B. The major energy transfer from the exit crater formed by the Nano-diamond meteor into our atmosphere was steam, a greenhouse gas.

The time for the first significant sea level rise, MWP-1Ao, is reported as 19,000 YBP and the calculated debris impact times of supernovas HB 21 and W50 are 18,628 and 17,600 YBP, respectively. The second melt water phase, MWP-1A, began at 14,600 YBP and was caused by supernova CTB 109 . The CTB 109 supernova remnant has a declination in the northern hemisphere of 59 degrees and a modified eastern terminus of
81 degrees east longitude, see Table 3. CTB 109 has the closest supernova terminus to the longitude of eastern Arabia, but it did not produce the east Arabian melt that formed the Fertile Crescent shown in Figure 9. The timing of the meteor collision is an extraordinary win for SNIT because it shows how the nano-diamond meteor and the Vela supernova worked together to form the Fertile Crescent (Figure 7).

Supernova W50 is the largest supernova remnant, 700 lightyears across, and it left a black hole as the result of the explosion of a giant star [15]. The nano-diamond meteor that arrived near 12,800 ya was ejected from the W50 supernova. The nano-diamond meteor cut a tube that was connected to the interior molten mantle of the planet that supplied energy to the surface through the exit crater for 2,800 years. During the 2,800 year period, the Vela supernova added its combustible 
Table 1. Sea Level Rise and Supernova Impact Times [12,13].

\begin{tabular}{|c|c|c|c|}
\hline Sea Level Rise, SLR & Time SLR, YBP & Supernova & Impact time, YBP; Declination, degrees \\
\hline MWP-1Ao & 19,000 & HB 21(G89.0+4.7) & $18,628,+50$ \\
\hline & & W50 & $17,600,+5$ \\
\hline MWP-1A & & G109.1-1.0 (CTB 109) & $14,957,+59$ \\
\hline MWP-1B & 14,600 to 13,500 & Nano-diamond Meteor & 12,800 \\
\hline & 11,500 to 11,000 & Vela & $12,393,-45$ \\
\hline & & Cyprus Extinction & 10,000 \\
\hline & & & $8,004,+14$ \\
\hline
\end{tabular}

Table 2. Melt Water Phase Supernova Terminus and Red Sand Deserts or Shores.

\begin{tabular}{|c|c|c|c|}
\hline Sea Level Rise/Time & Supernova/Impact Time & Terminus Longitude & Red Sand location/Long. \\
\hline \multirow[t]{4}{*}{ MWP-1Ao/19,000 } & HB 21/18,628 & ET03 West & Morocco 06 West \\
\hline & HB 21/18,628 & WT177 East & Auckland/175 East \\
\hline & W50/17,437 & WT10 West & South Africa/14.33 East \\
\hline & W50/17,437 & ET170 East & Auckland/175 East \\
\hline \multirow[t]{4}{*}{ MWP-1A/14,600 to 13,500} & G109.1-1.0/14,818 & $\begin{array}{l}\text { WT97 West } \\
\text { North } 42 \text { Lat }\end{array}$ & Wyoming, USA/105 West \\
\hline & G109.1-1.0/14,818 & $\begin{array}{l}\text { ET80 East } \\
\text { North } 45 \text { Lat }\end{array}$ & Kyrgyzstan, /75 East \\
\hline & G109.1-1.0/14,818 (Mg Nods) & $\begin{array}{l}\text { WT85 West } \\
\text { South } 15 \text { Lat }\end{array}$ & Peru Basin Nodule \\
\hline & G109.1-1.0/14,818 (Mg Nods) & $\begin{array}{l}\text { ET80East } \\
\text { South } 16 \text { Lat }\end{array}$ & $\begin{array}{l}\text { Indian Ocean Nodule } \\
\text { Formation (IONF) }\end{array}$ \\
\hline MWP-1B/11,500 to 11,000 & Vela/12,386 & WT80 East & Kyrgyzstan, /75 East \\
\hline \multirow[t]{9}{*}{ MWP-1C/ 8,200 to 7,600} & W51C(G49.2-0.7)/8,004 & $\begin{array}{l}\text { ET120 East } \\
\text { North } 7 \text { Lat }\end{array}$ & Great Santa Cruz/ 122 East \\
\hline & W51C(G49.2-0.7)/8,004 & WT60 West South 45 Lat & Patagonian Desert/60 West? \\
\hline & W51C(G49.2-0.7)/8,004 & $\begin{array}{l}\text { WT } 60 \text { West } \\
\text { North } 10 \text { Lat }\end{array}$ & Guyana Offshore/59 West? \\
\hline & $\mathrm{G} 31.9+0.0 / 7,822$ & $\begin{array}{l}\text { ET115 East } \\
\text { North } 10 \text { Lat }\end{array}$ & Mui $\mathrm{Ne}, \mathrm{VN} / 108$ East \\
\hline & $\mathrm{G} 31.9+0.0 / 7,822$ & $\begin{array}{l}\text { WT65 West } \\
\text { North } 46 \text { Lat }\end{array}$ & Prince Edward Island/63 West \\
\hline & $\mathrm{G} 57.2+0.8 / 7,329$ & $\begin{array}{l}\text { ET130 East } \\
\text { South } 20 \text { Lat }\end{array}$ & Simpson Desert/ 135 East \\
\hline & $\mathrm{G} 57.2+0.8 / 7,329$ & $\begin{array}{l}\text { WT } 53 \text { West } \\
\text { North } 47 \text { Lat }\end{array}$ & ST John's Newfoundland/49 West? \\
\hline & $\mathrm{G} 57.2+0.8 / 7,329$ & $\begin{array}{l}\text { ET130 East } \\
\text { North } 47 \text { Lat }\end{array}$ & Heilongjiang China /125 East? \\
\hline & G57.2+0.8/7,329 & $\begin{array}{l}\text { WT49 West } \\
\text { South } 20 \text { Lat }\end{array}$ & Frono, Brazil/42 West \\
\hline
\end{tabular}

Table 3. Time Correction Supernova Western Terminus Longitude Location.

\begin{tabular}{|c|c|c|c|c|c|}
\hline Supernova & Right Ascension & Impact time, YBP & IWT, degrees Longitude & MIWT, Degrees Longitude & Declination, degrees \\
\hline HB 21 & $20 \mathrm{~h} \mathrm{43m}$ & 18,628 & $73 \mathrm{E}$ & $177 \mathrm{E}$ & +50 \\
\hline W50 & $19 \mathrm{~h} 11 \mathrm{~m} \mathrm{49s}$ & 17,437 & $50 \mathrm{E}$ & +5 \\
\hline G109.1-1.0 & $23 \mathrm{~h} 01 \mathrm{~m} \mathrm{35s}$ & 14,818 & $107 \mathrm{E}$ & $99 \mathrm{~W}$ & +59 \\
\hline Vela & $8 \mathrm{~h} \mathrm{35m} \mathrm{20.66s}$ & 12,393 & $110.5 \mathrm{~W}$ & $80 \mathrm{E}$ & -45 \\
\hline W51C & $19 \mathrm{~h} 23 \mathrm{~m} \mathrm{19.3s}$ & 8,004 & $50 \mathrm{E}$ & $97 \mathrm{~W}$ & +14 \\
\hline G31.9+0.0 & $18 \mathrm{~h} 48 \mathrm{~m} 25 \mathrm{~s}$ & 8,092 & $44 \mathrm{E}$ & $67 \mathrm{~W}$ & -0 \\
\hline G57.2+0.8 & $19 \mathrm{~h} \mathrm{35m}$ & 7,498 & $51.5 \mathrm{E}$ & $52 \mathrm{~W}$ & +21 \\
\hline G43.3-0.2 & $19 \mathrm{~h} 11 \mathrm{~m} \mathrm{08s}$ & 1,551 & $50 \mathrm{E}$ & $29 \mathrm{E}$ & +9.1 \\
\hline
\end{tabular}

energy of incoming lighter elements that equaled the amount of geothermal energy from the exit crater.

Figure 8 was produced by Dr. J. Kennet. The missing part of Dr. Kennet's meteor collision theory is the concept of an exit crater. The impact crater was the Tone Sap Lake in Cambodia that is in a tektite field that Dr. O'Keefe proposed as moon debris. Tektites are in strata dated near 12,800 years ago and the incoming angle for the meteor to penetrate the moon and the earth indicates W50 as the meteor producing supernova. The exit crater became the basin of the Black Sea. The nanodiamond meteor travelling at $70 \%$ the speed of light penetrated the moon, caused the formation of the tektites and blasted them 
to earth, penetrated the crust of the earth at the Tone Sap Lake in Cambodia, and exited the mantle at the Black Sea blasting out the debris field shown in Figure 8 that caused the North and South American extinctions. The primary result was that the basin of the Black Sea became the hottest spot on earth and the melting ice in the area produced the water via rain and heat that formed the Fertile Crescent. For many years, the region south of the Black Sea was the warmest area on earth and as a result supported the first farming culture and cities.

The Fertile Crescent began supporting a farming culture rather than a hunter gathering culture for mankind and the change of life style resulted in a Garden of Eden when compared to the previous cold planetary condition that could not support crop production and forced mankind to be hunter gathers. It could be said that the Fertile Crescent became a land flowing with milk and honey after 10,000 YBP.

Steam formed from melt water was departing the exit crater and warming earth's atmosphere since 12,800 YBP but it was not enough water flow into the crater to break the aridity of the region until 11,000 YBP. Near 11,000 YBP the Bosphorus Straight opened to allow sea water from the Mediterranean Sea into the exit crater providing enough water to be converted into steam to change the aridity in the region. The increased water flow into the exit crater provided a bottom deposit of silt and enough cooling to produce solidified lava to resist energy transfer from the hot magna to the water in the bottom of the Black Sea and stop the warming from the unlimited geothermal heat source. This is a very challenging heat transfer problem and could have taken a thousand years to reach equilibrium (Figure 7).

It is necessary to visualize the tube of the meteor's path to the liquid magna under the mantle as a conveyor belt with cooled denser mantle going down and hotter lighter mantle going to the surface. The hot mantle arriving at the surface brings geothermal energy to melt the ice of the planet and greenhouse gases particularly carbon dioxide to increase the use of solar energy in the process of melting the polar ice fields.

The large increase in steam at 11,000 YBP when the Bosphorus Straight allowed flow into the exit crater not only changed the aridity of Eastern Arabia, it also overcame the cooling phase of the Vela supernova, (Figure 7), and caused the Cyprus

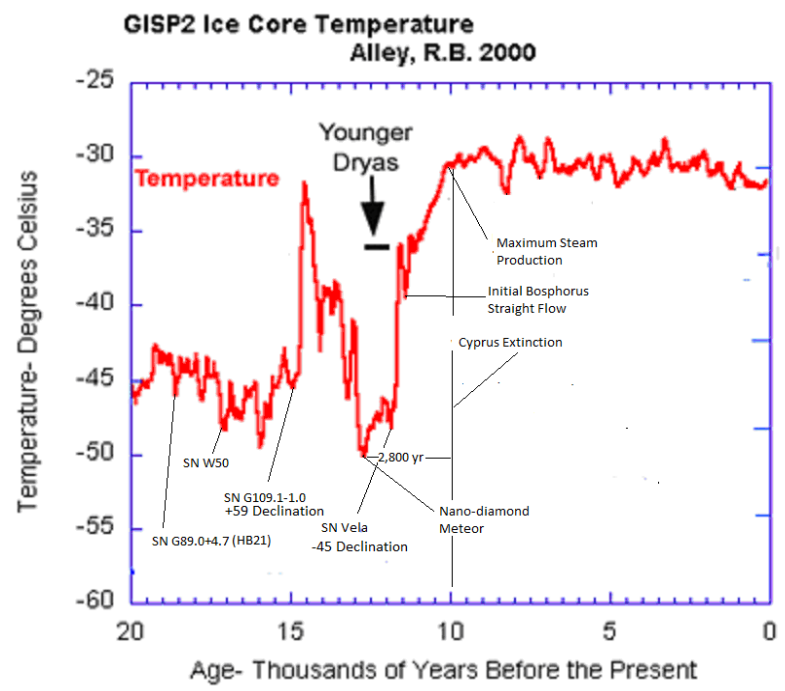

Figure 7. Greenland ice core temperatures_nano-diamond meteor and supernovas [14].

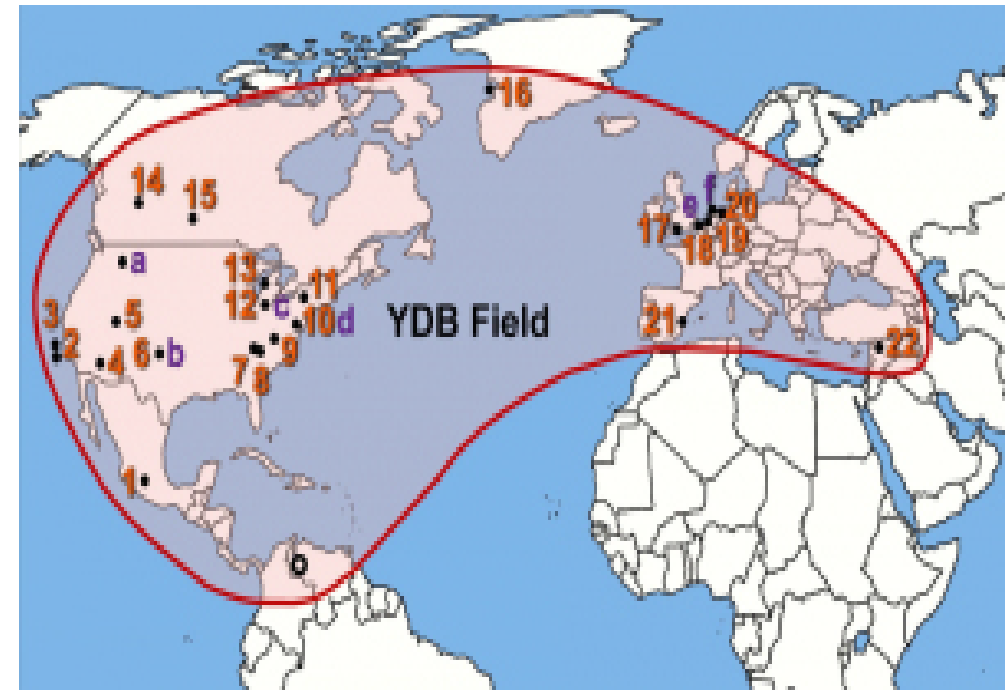

Figure 8. Nano-diamond Meteor Debris Field and Exit Crater. 
extinction. Oxygen breathing species had a chance to survive if they could exist in deep caves or could escape the steam infested region, but on an island like Cyprus with restricted change of location, extinction due to excessive steam in the atmosphere for oxygen breathing species was a certainty. The time quoted for the actual extinction was 10,000 YBP indicating that the maximum extent of the steam from the exit crater that caused the suffocation of the animals occurred 1,000 years after water flow into the crater from the Bosphorus Straight.

\section{Formation of Oil fields and Red Sands}

The desert in southeastern Arabia is the largest sand desert in the world and a large deposit of red sand exists in southeastern Saudi Arabia [17]. The red sands are accumulations of meteors of mixed silicon and iron from supernova impacts that were completed over a relatively short period of time. Since Saudi Arabia has the world's largest oil deposits and largest red sands desert, It is proposed that the locations of deserts and red sands will correlate with the locations of major oil fields. Other deposits of red sand should exist at different longitudes that match with termini of other supernovas and oil field locations. Some of the locations of red sand deposits produced by the melting of the Wisconsin Glaciations' supernovas are shown in Table 2.

The correlations for the red sand longitudinal locations with the modified western and eastern termini of the supernova remnants and the debris impact times with the sea level rise times are excellent. The accuracy for the red sands deposits for the modified western termini, MWP-1C supernovas is extraordinary and indicates an oil deposit produced by the supernova will be near the modified termini. The largest silt deposits for supernova debris accumulated in the ice of the Wisconsin Glaciations will be at the western terminus because solar energy input occurs at the same time and location increasing the rate of melt. A melt that occurred in the winter time produced the red sand desert in Wyoming, USA.

\section{Modified Termini Locations and Oil Fields}

When considering recent debris stream impacts for SN1006 and SN 1054, it is not necessary to modify the locations on the planet due to the changing right ascension of the supernova remnant's termini with time. When predicting termini locations at impact times thousands of years in the past, an increase of 5.5 minutes per century applies to the right ascension value of the remnant [18]. In Table 3, the ideal western terminus location, IWT, was calculated for today's right ascension of the supernova remnant and then modified by the stated drift to produce the modified ideal western terminus location, MIWT at the year of impact.

A plot the modified western and eastern termini for the melting supernovas of the Wisconsin Glaciations of Table 3 and G43.30.2 is shown in Figure 10 on a world map showing oil deposits. The vertical black lines are MIWT and the vertical red lines are modified ideal eastern termini, MIET. Depending on northern or southern hemisphere entry the MIWT can move to the west or east indicated by the arrows, respectively; but the MIET tend to be stationary. It is certain that oil fields have been produced by other supernovas, but a reasonable correlation exists for the supernovas being studied.

The question as to where the energy comes from that causes global warming is answered by Figure 10 . Some of the incoming carbon and hydrogen particles of the supernova debris streams of atomic size burn in the atmosphere causing heating. The carbon, helium, and hydrogen that did not burn in the atmosphere passes through the biosphere and mantle to form oil deposits at a depth of upto three kilometers where oil traps are available. The incoming energy to our atmosphere is not manmade and reducing manmade carbon emissions will not correct the problem of higher temperatures and increasing carbon dioxide concentration in the atmosphere.

The recurrent nova WZ Sagittae has a western terminus of 63 degrees east longitude and red sand deposits exist in the Kharan Desert in western Pakistan at the same longitude. Pakistan has

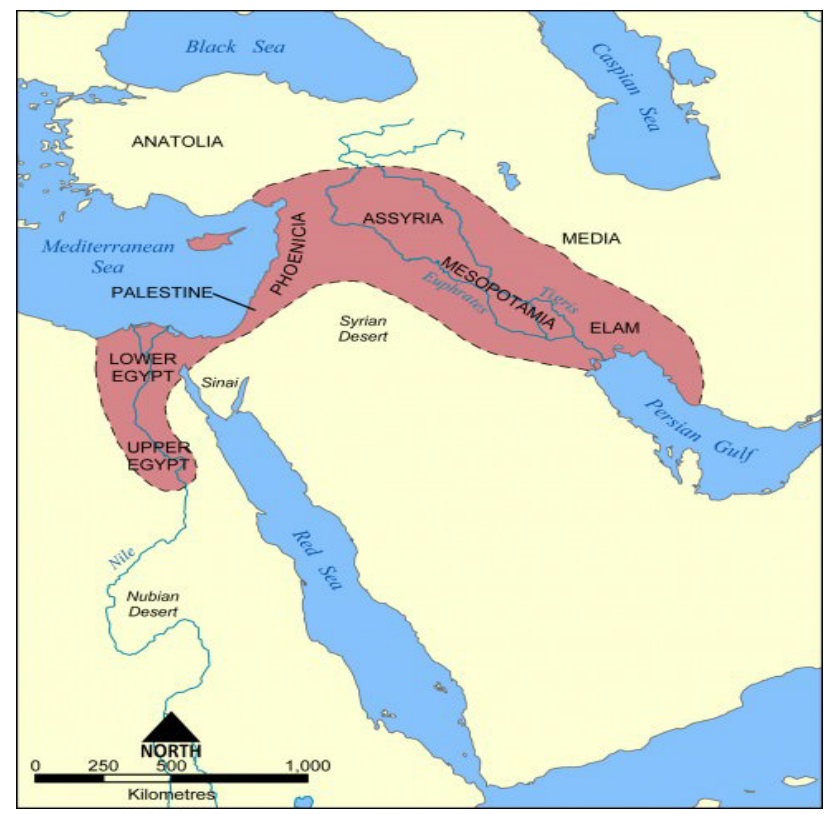

Figure 9. Fertile Crescent [16]. 
large oil reserves that have been recently discovered [20]. Since the recurrent nova WZ Sagittae has been impacting earth for hundreds of years, oil should have been deposited at its western terminus. The corresponding oil fields for the eastern terminus are in Baja, Mexico.

Figure 11 shows the correct rectangular locations for the SNIT creation of oil fields for SN G57.2-0.8. The blue lines represent a tolerance on the accuracy of longitudinal location. The red sands denoted by the red circles are missing for the northeast corner of the rectangle, but the northeast corner coincides with the largest oil field in China at Heilongjiang.

Figure 12 shows the correct rectangular locations for the SNIT creation of oil fields for SN G49.2-0.7 or W51C. Only three corners of the rectangle have discovered oil fields. One corner, suggesting an undiscovered oil field, is missing in the ocean south of Australia.

\section{Great Ape Extinction and out of Africa Migration}

The great ape became extinct 100,000 years ago. The change in $\mathrm{CO}_{2}$ and $\mathrm{O}_{2}$ concentration in the atmosphere produced by the iron eating alga caused previously forested areas to become savannas reducing the great apes natural habitat and causing its extinction [21].

The extensive iron deposit in Zambia, Africa near 110,000 years ago by the Monogem Ring supernova shown in Figure 6 caused extensive storms and death in southern Africa. The planet was also cooling at the time. These factors caused the human population indicated by the red area in Figure 13 to migrate northeast into Israel which in time became part of the Fertile Crescent that supported the first cities.

\section{Deserts, Oil, Red Sands, Debris Streams}

The realization that carbon, hydrocarbons, silicates, and iron all enter our biosphere in nova and supernova debris streams is hard to deny when considering the data presented in this work. When looking at Figure 14, it is easy to believe that the geography of the northwest corner of India was produced by an incoming supernova debris stream and the associated high velocity, atomic particles of hydrogen, helium, and carbon penetrated part of the mantle to form oil deposits. Silicon is an element that is also abundant in an exploding star, but the particles were

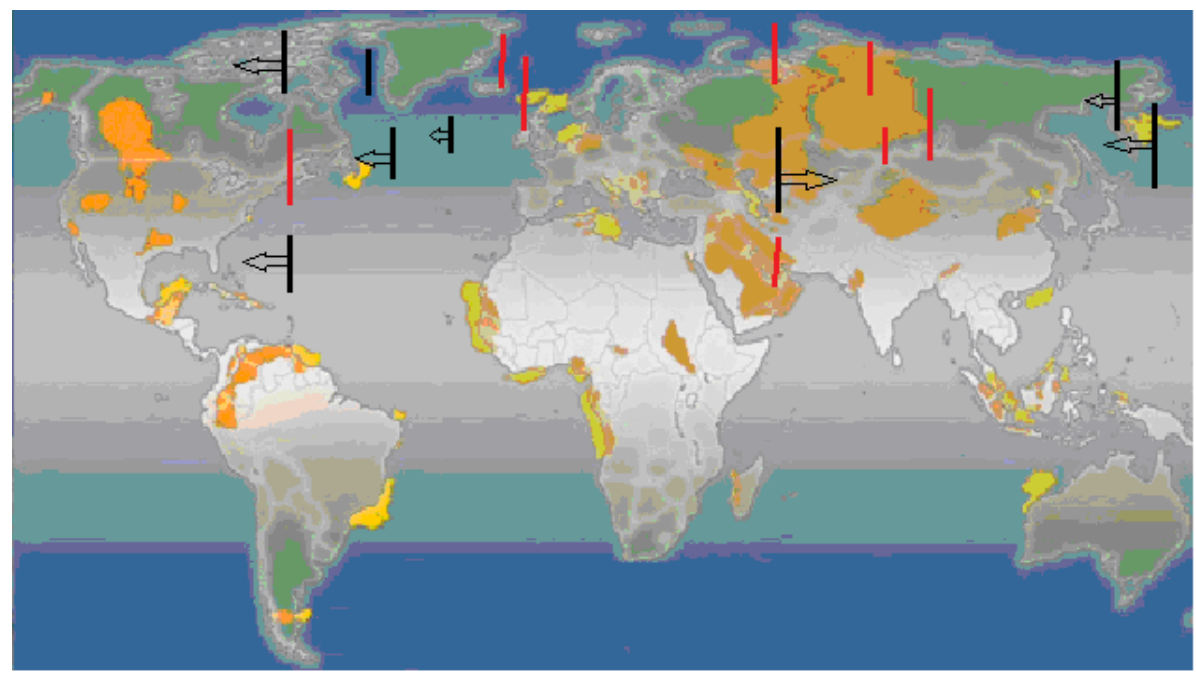

Figure 10. Modified Ideal Western and Eastern Termini with Heavy Oil Locations [19].

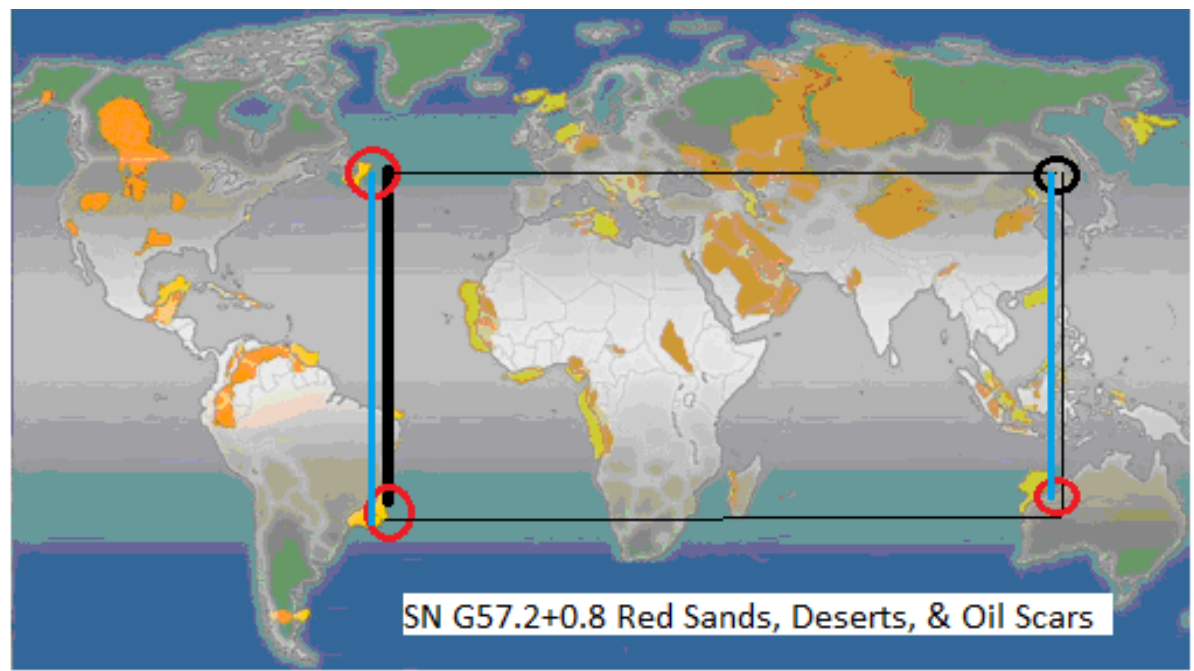

Figure 11. Rectangular Locations for Supernova G57.2+0.8 Oil Fields. 


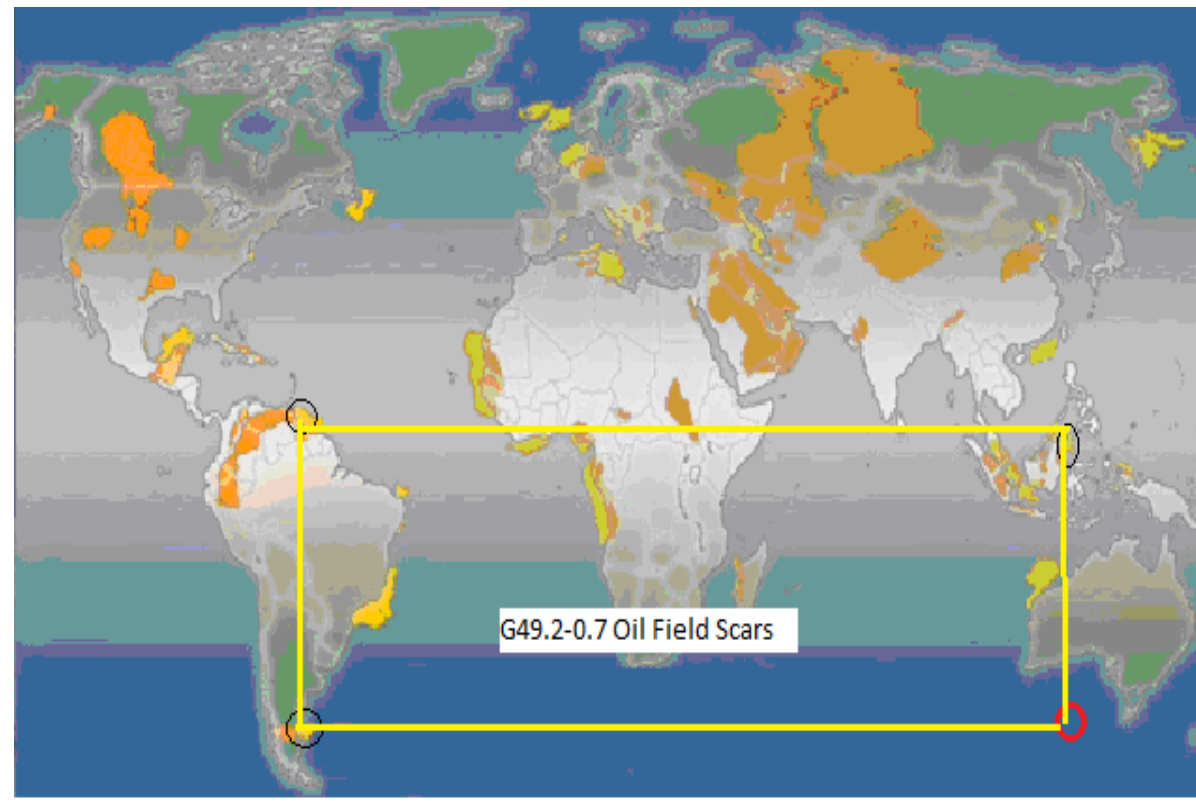

Figure 12. Rectangular Locations for Supernova G49.2-0.7 Oil Fields.

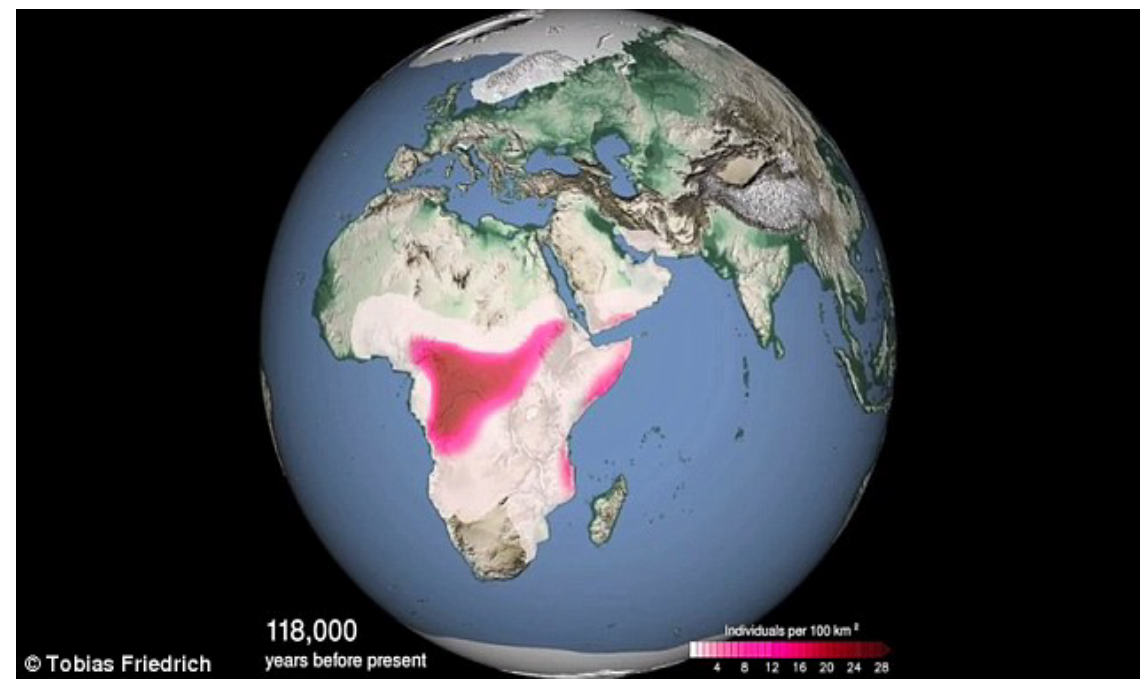

Figure 13. Human Population 118,000 Years Ago [22].

larger and traveling at less velocity and as a result sand formed on the surface and formed the desert in the impact area. Iron is the last abundant element formed before a star explodes and at times is mixed with the silicon to form red sand. It is probably not a coincidence that the largest sand desert in the world is associated with the limitless oil deposits of Saudi Arabia.

Supernova Puppis A with a -42 degree declination, southern hemisphere, and a 32 degree eastern longitude for its modified northeastern terminus with a small deflection to the east is a promising candidate as the creation device of the extensive deserts and Saudi Arabian oil fields, see Tables 2 and 3 [13]. The date of impact 2,766 years ago is very close to the date of the fall of Babylon (44.5 east longitude) 539 BC, Fall of third intermediate period of Egypt 2,712 years ago, and the collapse of Dilmun civilization [37]. The major questions are: How long does it take for hydrogen, carbon, and helium to form crude oil at depths of 3 kilometers in earth's mantle?; Did the surface deposit of normal sands and red sands that created the Saudi Arabian deserts via the eastern terminus of the Puppis
A supernova destroy the advanced civilizations of the time?; Since the light of the Puppis A supernova explosion was seen 3,700 years ago, did Isaiah have the scientific tools to produce his famous prophecy concerning the destruction of Babylon by the supernova debris stream? The supernova Puppis A debris stream placed the elements for oil production and sands in and on the mantle of Saudi Arabia 2,766 years ago well after Isaiah's prophecy.

\section{Moving deflected Focal Point of SN 1006}

If any country should be interested in protecting their country from the coming phenomenon predicted by SNIT, it should be India because atomic hydrogen is already burning in their sky in the summer months. It is difficult to see what is next for India, but when heavier particles compose the SN 1006 debris stream, the hotspot of India's summers should move northwest. The hotspot for India's summer of 2015-16 is represented by the green star in Figure 15.

The deflections of western termini for the SN 1006 debris 


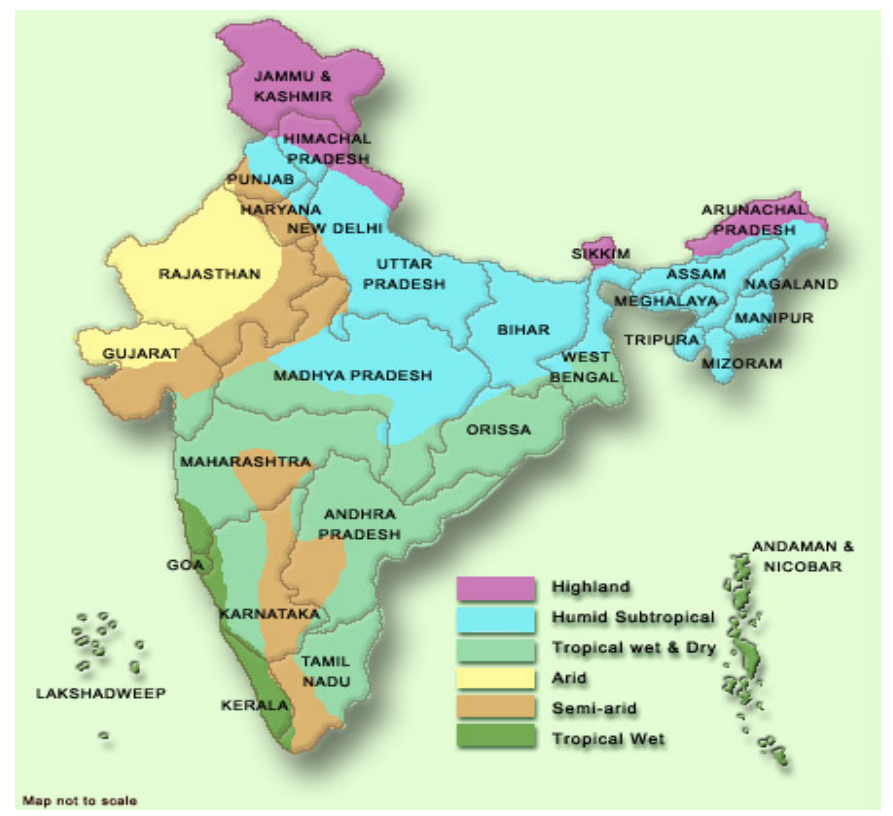

Figure 14. Varying Climate of India [23].

streams of different years are shown in Figure 15. SN 1006's northwestern focal point has provided SNIT with an interesting amount of data since the beginning of the SN 1006 impact near the year of 2012. The motion of the northwest focal point is represented in Figure 15 by three stars: blue, carbon stream large ice melt in Greenland 2012; Black, helium stream- Siaga antelope deaths 2014; and Green, hydrogen stream - India's excessive summer temperatures 2015-16. In the last two weeks of May and first week of June 2017 Europe, Asia, and the Middle East experienced one the most extraordinary heat waves in world history. The hottest temperature for May 2017 was in Pakistan at 128.3 degrees Fahrenheit [24]. The hotspot has repeated for three consecutive years and was moving southeast, but now it appears to be moving slowly to the northwest.

As the atomic mass of the debris stream particle decreased, the northwest terminus of SN 1006 was deflected farther to the east and to the south. This can be explained as a simple physics reaction caused by the sun's magnetic field. As the northwest focal point moved east and south, the southwest focal point moved east and south and caused extreme melting of Antarctic sea ice in November of 2016 when it resided over the Antarctic sea ice. The good news for India is as the particle atomic mass increases in the debris stream of SN 1006, the northwest focal point will move to the northwest.

The bad news is if this happens and excessive melting of the Greenland ice is in the future when carbon particles become dominate in the debris stream. At that time some relief of rising sea levels is possible because the Antarctic melting due to SN 1006 will cease.

\section{Tornado Outbreaks and Sn- Nova Debris Stream Arrival Times}

In the section El Nino Scientific Logic, three tornado outbreaks were discussed and SNIT notes the western terminus debris stream for WZ Sagittae is flowing in the correct direction between the earth and sun during the month of May to produce a maximum number of tornadoes and cause the high SSTs of an El Nino in December [25]. The sign of the El Nino, high SSTs west of South America, is seen in Figure 16 for year 2003 that produced a record number of tornadoes in May.

The tornado outbreak that holds the current record for tornadoes in one month is April 2011. It is noted that this year is not an El Nino year, but the third tine appears in Figure 17 in the Atlantic Ocean in April 2011, a possible arrival time of SN 1006's debris stream. This could be a sign of an El Nino event if the ocean area was not restricted to the Pacific waters west of South America in December. The new location for the sign of the El Nino event occurs because SN 1006 has a different right ascension than the three novas that have been credited with El Nino events causing the high SSTs west of South America. This tornado outbreak became the record because SN 1006 is the strongest type supernova possible and the tornadoes occur in tornado season.

An unusual tornado outbreak occurred in November 2005 that included 79 tornadoes out of tornado season.

The third tine is shown in Figure 18 and occurs as a result of SN 1054 debris stream impact. The high SSTs in Figure 18 are at lower latitudes than the pacific water surface latitudes acceptable for an El Nino event. The tornado outbreak occurs on November 15 at a location of the focal point before the western terminus date of December 12 is reached and would be equivalent to a 27 degree longitude shift to the east from the western terminus of SN 1054. If 27 days were added to December 12 like the SN 1054 focal point was traveling east from its western terminus the date would be January 8 that misses the CAM date of WZ Sagittae of January 20 by 12 days or 12 longitude degrees. This simple calculation shows why the locations of the hotspots in Figure 18 are nearly the same as the hotspots defining WZ Sagittae's eastern terminus [25].

The incoming debris stream provides the particle funnels adding to the number of tornadoes occurring in an outbreak and 


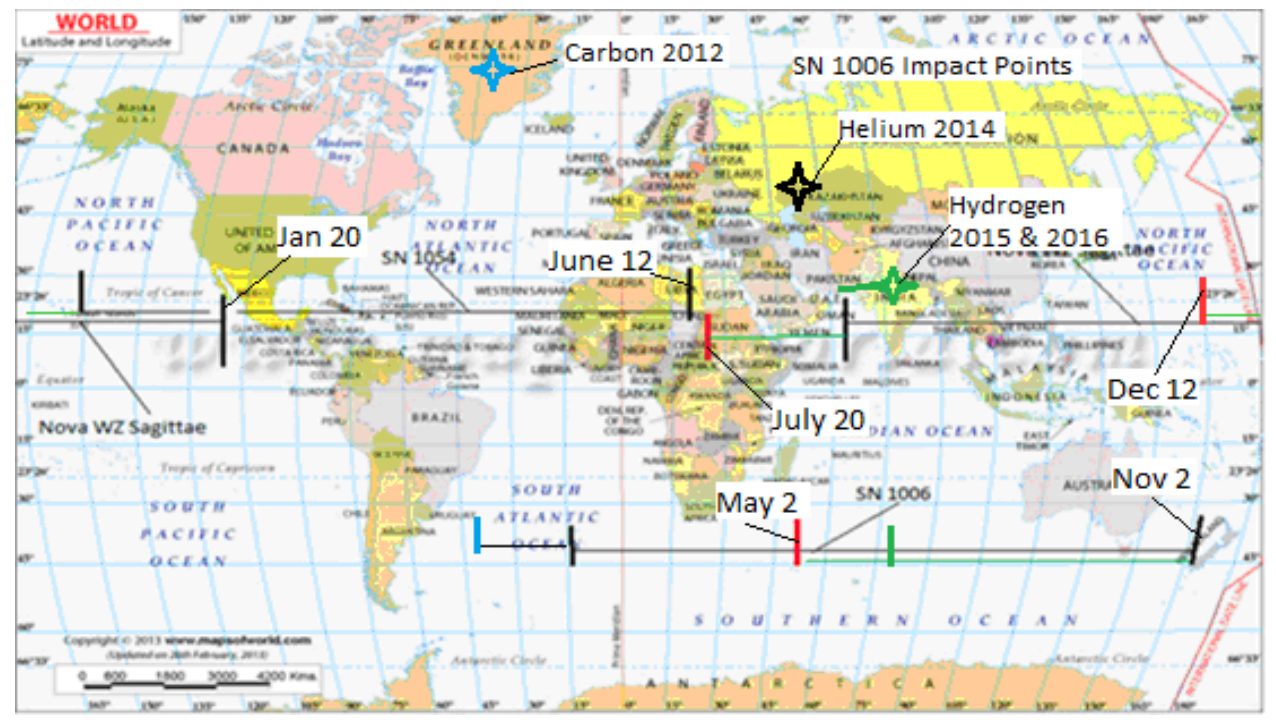

Figure 15. Deflected Western Termini of SN 1006 Debris Streams.

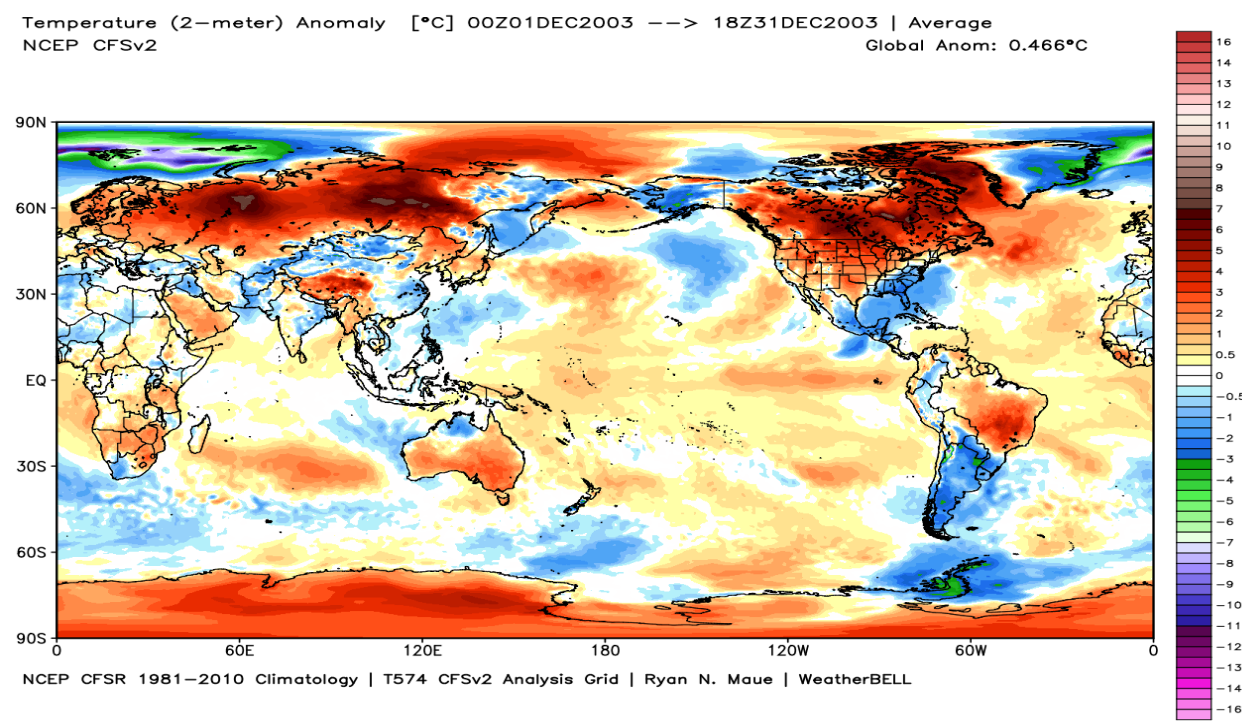

Figure 16. WZ Sagittae 2003 El Nino [26].

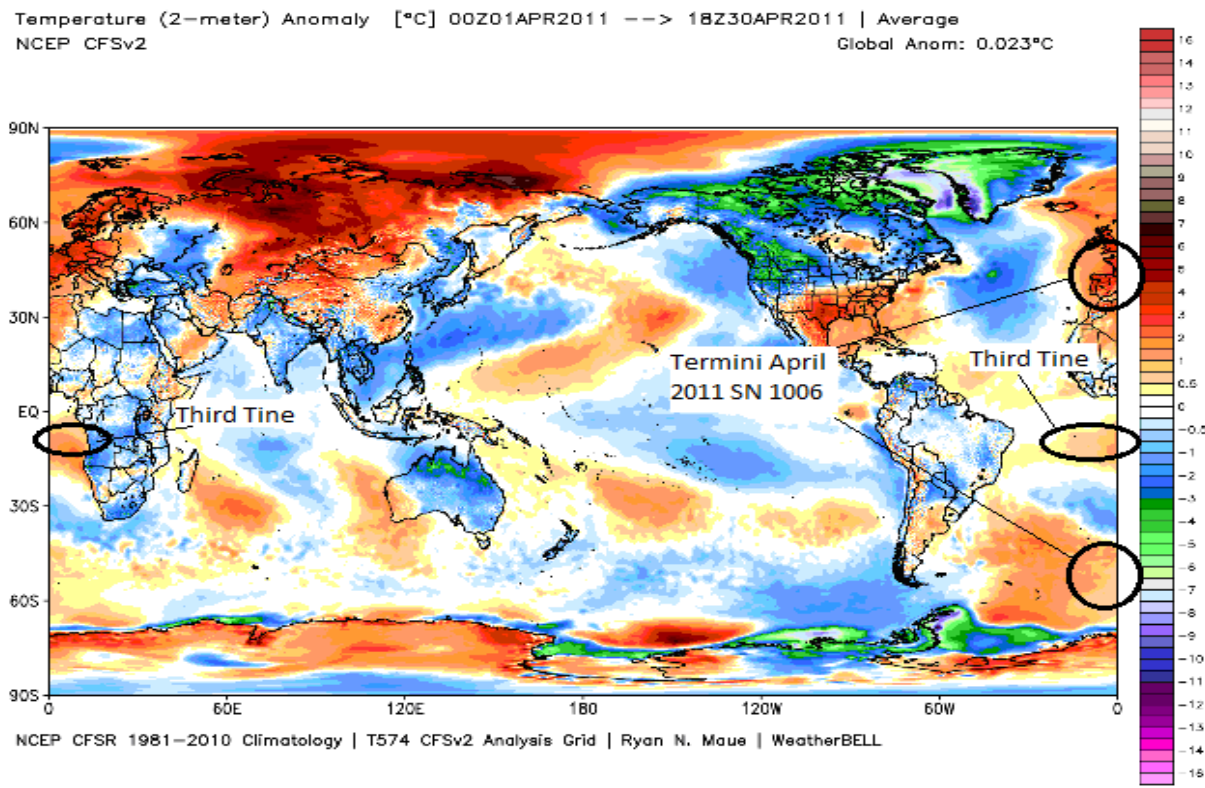

Figure 17. SN 1006 Month of Super Tornado Outbreak 2011 [26]. 
generally the debris stream tornadoes are stronger due to the debris stream's higher particle velocity.

\section{Debris Entry Conditions}

The question asked by Dr. Dukes of Purdue University was: Why do the focal points or termini exist at one longitude and two north and south latitudes on the planet at a prescribed time rather than in two bands at north and south latitudes all around the planet? The answer is that incoming particles that penetrate in large numbers as required at a focal point must satisfy a perpendicular condition with earth's magnetic field to penetrate to a lower altitude. Some particles that satisfy the entry condition will penetrate the outer magnetic field of earth and become trapped in a magnetic bottle to form the north and south termini. Other particles of a more powerful impact that satisfy the entry condition will come straight through and form the third time. A few particles that do not satisfy the entry condition will penetrate at other longitudes but not in large numbers, this condition has been called the Duke's effect.

The other condition for maximum particle density for the impacting debris stream is that the orbital position of our planet's maximum diameter aligns with the sun, remnant line. The two directions of our planet's orbital path toward and away from the sun, remnant line will reduce particle density.

The perpendicular entry condition exists for a short time for each day the planet resides in the debris stream. The high temperatures that existed during the death of the Saiga antelopes in 2014 lasted for nearly a month and the maximum death rate of the antelopes was concentrated into a few days noted from May 6 to 27 in Figure 19. The 22 day hot spell indicates the period of time when earth was located in the incoming outer space debris stream from SN 1006. The calculated longitudinal location of the focal point that caused the deaths changed everyday earth was in the debris stream. Even though a specific longitude is calculated for the focal point, the actual focusing will occur over a circular area.

The same theoretical argument applies to the packed lower average temperatures in Alaska 2016 in Figure 21. Even though the remnant of nova WZ Sagittae and its debris stream passes over Alaska every day; a period of approximately a month, mid-November to mid-December, of the year provides the correct focusing particle conditions for the debris stream of WZ Sagittae to affect the average atmospheric temperatures of Alaska. The incoming particle density is maximum at termini locations and minimal in the region exterior to the 180 degree zone that does not include the debris focal point and varies in a sinusoidal fashion within the 180 degree focal point region between the termini.

\section{Interstellar Meteor-Impact and exit craters- Mud volcanoes- Tektites}

It is difficult to imagine a large mass travelling a distance of 18,000 lys from the explosion of the W50 supernova of age 20,000 ya at $70 \%$ of the speed of light that penetrated the moon, caused a tektite field in Cambodia, penetrated the earth causing the impact crater (Tone Sap Lake) and an exit crater (Black Sea basin), plus the debris field off Figure 8 testifying to the
North and South American extinctions. The meteor was in our solar system for less than thirty minutes but left enduring marks on earth. It provided the major amount of energy to end the Wisconsin Glacitions and produced steam to end the aridity at 111,000 ya in Eurasia.

A major scar left by the meteor was the debris field of Figure 8 as it left the exit crater, the Black Sea basin, on its way to outer space.

A particular case of interest refers to the Australian tektites dated as 700,000 years old but contained in strata dated as 24,000 to 16,000 years old, Lake Torrens Formation, or 16,000 to 12,000 years old, Motpena paleosol, [27,28]. The youngest earth strata containing the tektites give the time when the tektites fell on land and impacted with a large velocity penetrating into earth strata older than the impact time. The boundary between the mid-Holocene Alluvial Sands and the Motpena paleosol gives the minimum date of 12,000 years ago as the logical choice for the time of the fall of the tektites because one tektite was found at this boundary. This tektite strata date is very close to the nano-diamond meteor event noted as 12,800 ya.

Dr. O'Keefe's moon tektites theory was debunked because the moon rocks found on the surface of the moon did not have the same composition as the tektites. If the tektites came from deep within the moon, the composition would not be the same as surface rocks.

The mud volcanoes in the Black Sea and Caspian Sea were caused by the interstellar meteor when it connected the surface of the planet by a lava tube to the molten rock below the mantle. The lava flow was always to the northwest in the tube because that was the direction of travel of the meteor. The result was mud volcanoes and underground lava eruptions 300 miles from the nearest natural volcano located at the Eurasian plate boundary [30]. A line drawn through the two mud volcano locations in Figure 20 comes very close to intersecting Tone Sap Lake in Cambodia.

Tone Sap Lake is a wonder in the fact that it is the largest lake in Southeast Asia. It is oblong and its major axis points toward the two mud volcano locations. The basin of the Black Sea is also oblong and its major axis generally points in the same direction. It is proposed that these scars on earth were all left by the actions of the interstellar meteor from SN W50 whose remnant is 700 lys across indicating the size of the star that exploded to produce the meteor [32].

The Black Sea basin is the youngest exit crater on earth and was the last major geothermal hot spot.

\section{Proof Ending Carbon Stream- wz Sagittae}

In reference [34] section 8 entitled Drought, The theory was presented that incoming carbon particles in a nova or supernova debris stream would cause drought when a terminus coincided with the time of year for the rainy season at a particular region. The California drought caused by WZ Sagittae was given as an example and it ended in the winter of 2016-17. Figure 22 shows the proof of the debris stream's carbon particles being absent over Alaska during the winter of 2016 when the drought ended in California. In previous years, the exothermic reaction of the 


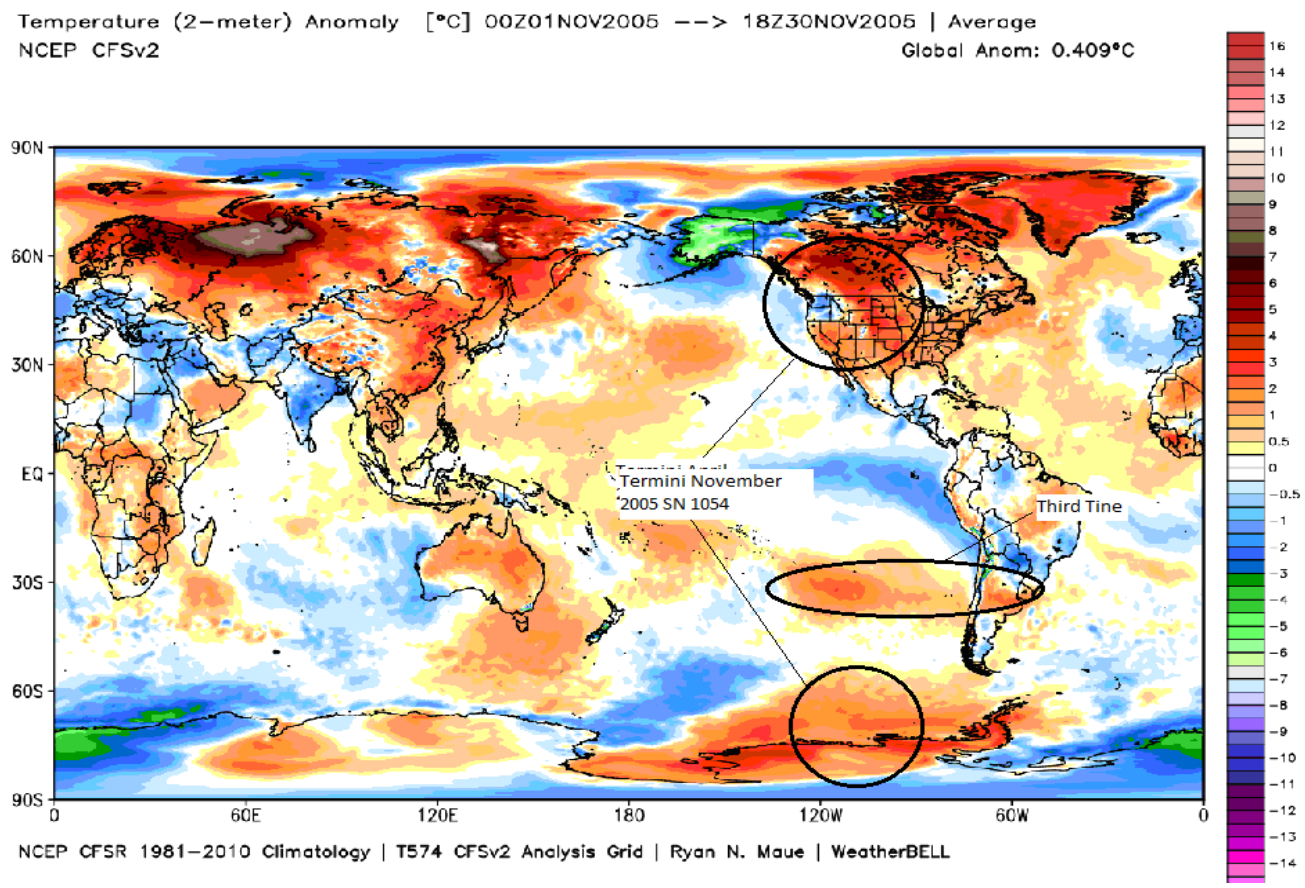

Figure 18. SN 1054 Impact Debris Stream Tornadoes [26].

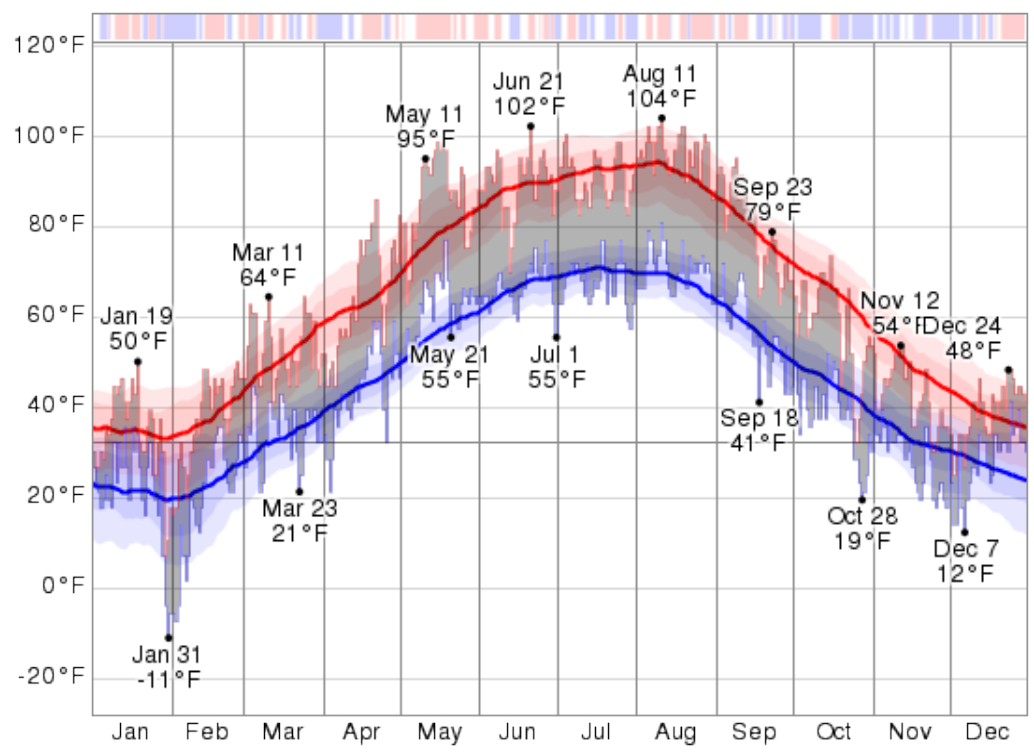

Figure 19. May 6 to May 28 Longest Warm Spell Kazakhstan 2014.

burning carbon particles of the incoming debris stream that disassociated water molecules elevated the average temperatures at the time of the last group of blue data points shown in Figure 22 for the Alaskan region. In 2016, the exothermic reaction of burning carbon entering in the WZ Sagittae debris stream was absent giving lower daily average temperatures over Alaska from mid-November to mid-December.

Alaska's longitude is west of California, but the eastern terminus of WZ Sagittae is east of California. The decrease in average temperatures were measured in Alaska, but a similar measurement at lower western longitudes would have shown lower average temperatures at later dates but before January 20 to an area slightly east of $115 \mathrm{WL}$ due to the circular form of the area of the terminus region. In addition to the disassociation of water molecules, the lower average temperatures reduce the atmosphere's ability to hold water vapor over the noted area of western North America and the result is more precipitation in the region during the winter months.

The range of longitude for the designated temperature points in Alaska is 170 (ST. Paul, AK) to 140 west longitude, WL. WZ Sagittae eastern terminus, ET, is $115 \mathrm{WL}$ with a CAM date of January 20. Using the one day per degree longitude rule for the motion of a debris stream focal point, $170 \mathrm{WL}$ is 55 degrees from the ET and 55 days before the CAM date is November 25. The other boundary of Alaska at $140 \mathrm{WL}$ is 25 degrees from the ET and 25 days before the CAM date is December 26. The vertical black lines show the ideal time locations, November 25 and December $26^{\text {th }}$, for the focus of WZ Sagittae debris stream at both east, west designated temperature points in the main area of Alaska. The vertical red lines show the extreme cold 


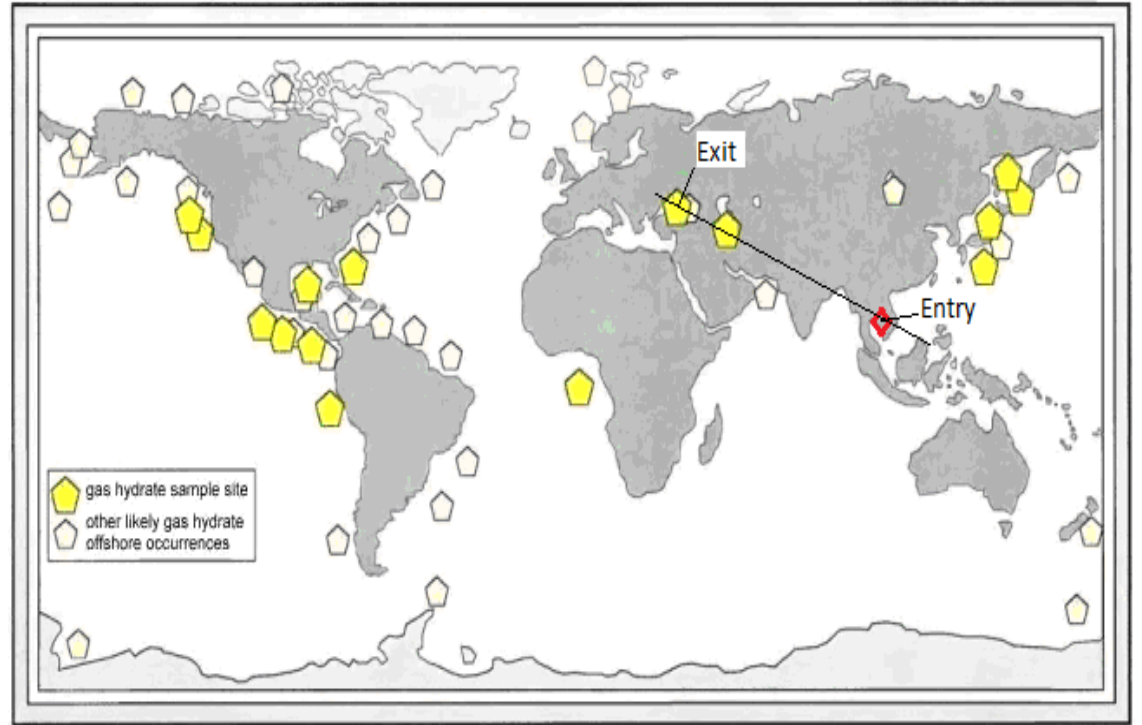

Figure 20. Worldwide Locations of Mud Volcanoes_Nano-diamond Craters [29].

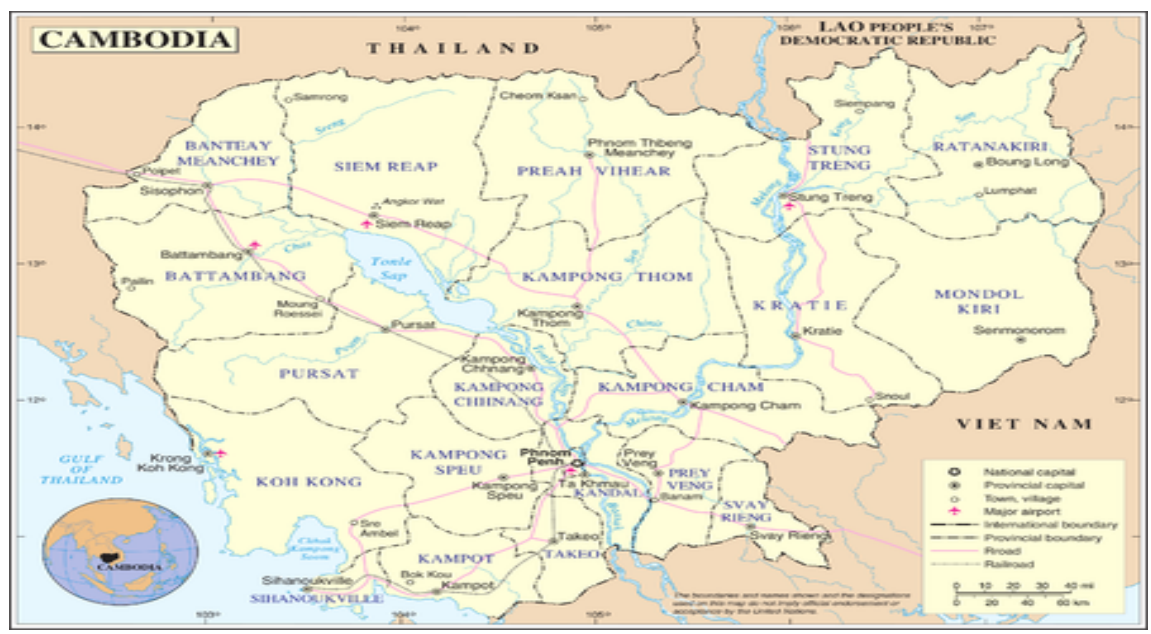

Figure 21. Cambodia with Tone Sap Lake [31].

Alaska daily temperatures 2016

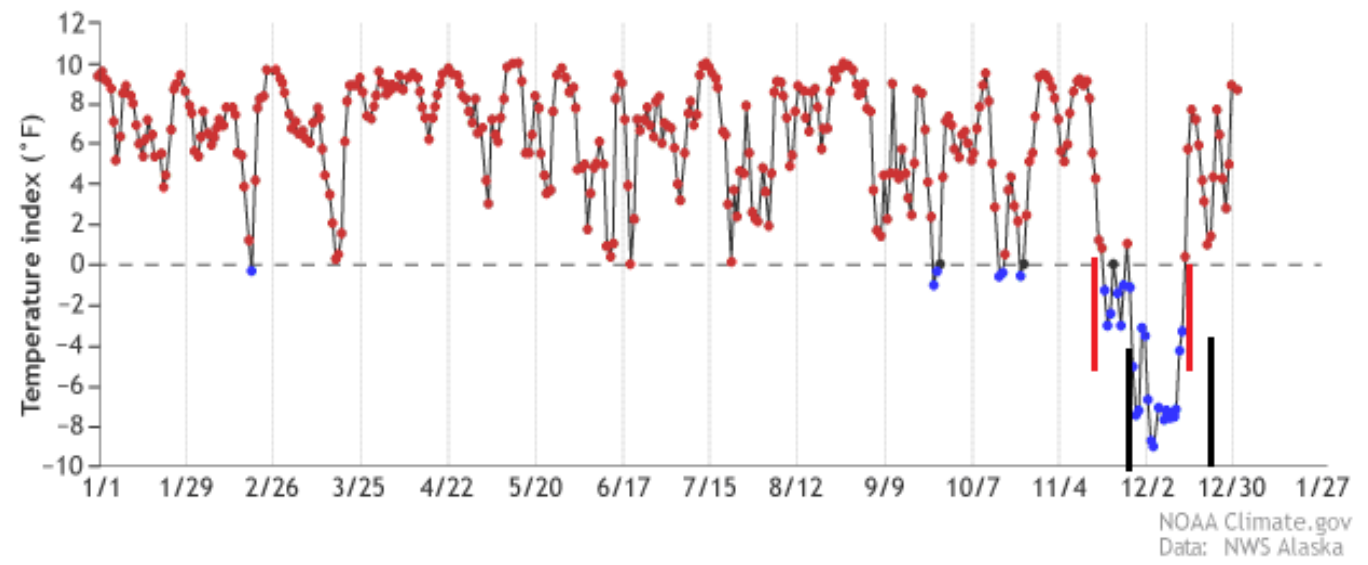

Figure 22. Excursion Alaskan Average Temperatures [33].

dates when according to the data the focus of the debris stream was over Alaska beginning in mid-November. The difference between the theoretical analysis and the data could be due to the carbon particles having a deflection, 10 degrees, to the west in the northern hemisphere that is not included in the analysis. This would shift the theoretical longitudes 10 degrees west giving the dates of November 15 and December 16. It is shown that the change of thermal characteristics of the WZ Sagittae debris stream causes the strange variation of consecutive days of below average temperatures in Alaska and the stated deflection provides the necessary accuracy.

A prediction occurs due to the previous calculation. From 
December 16, last date of low average temperatures in Alaska, to January 20, CAM date for ET, is 35 days. Since the debris stream reverses direction at the time of the CAM date of the ET in 35 days after Jan 20, the average temperatures should begin to decrease again over Alaska near February 24, 2017 and the trend should last until March 26. The times for cooler than average temperatures in Alaska, mid-November to mid-December and February 24 to March 26, will repeat annually until 2020-21 when the energy characteristic of the WZ Sagittae's debris stream change due to a new impact of a super outburst.

\section{Sea Ice Freezing at the North Pole and Melting at the South Pole 2017}

In reference 25 , I state "The incoming particle debris streams from WZ Sagittae, a recurrent nova, and minimum solar flux control the shape of the Arctic ice cap". Since the carbon particles have stopped for the incoming WZ Sagittae debris stream, the lack of their exothermic reaction caused the lower average temperatures in Alaska and the end of the drought in California. The absence of incoming debris stream energy for WZ Sagittae indicates cooling will increase at the northern ice cap near the dates of January 20 and July 20 the eastern terminus and western terminus of nova WZ Sagittae, respectively and cause increasing sea ice area near these dates. This trend should continue until the 2020-21 impact of the new debris stream from WZ Sagittae occurs. Increasing sea ice area in the Arctic will also occur near the termini dates of May $2^{\text {nd }}$ and November $2^{\text {nd }}$ of SN 1006 whose focal points are moving south causing increased melting in the Antarctic and increase freezing in the Arctic. This trend will continue until SN 1006's incoming carbon stream particles stop approximately 40 years from 2017.

The blue line representing the year 2017 in Figure 21a shows increased sea ice area in the Arctic for 2017 above line for 2016 before and after May $2^{\text {nd }}$. The blue arrow notes the increased ice area before and after July $20^{\text {th }}$ caused by nova WZ Sagittae that is a small change compared to the previously mentioned increase caused by SN 1006. These dates as termini where the incoming particles in the debris streams are focused [13]. In this case the particles delivering heat to the Arctic ice cap density was higher for the years preceding 2017. The WZ Sagittae debris stream's carbon particles stopped in the end of 2016 and thee focal point of SN 1006 is moving south.

In Figure 21b, the red line is for the year 2017 and the November $1^{\text {st }}$ date is the CAM date when the earth crosses the SN 1006 debris stream maximum focus for the second time in its yearly orbit. The ice is increasing in the green cross hatched area due to the absence of heating particles because the SN 1006 debris stream has moved to the south from the 2016 location.

The black stars in Figure 23(a,b) show that the locations of the maximum ice recovery agree with the CAM date of maximum heat lost in the Arctic region between years 2016 and 2017 for SN 1006.

The large melt in Antarctica that occurred in November of 2016 will repeat in the same month for 2017 and will be displayed by NASA in the Antarctic sea ice report of early December 2017.

\section{Triple Plague Locations Nova Wz Sagittae and Altitude}

The section disease transmission in reference 25 shows a concentration of plague cases near the continental divide of the USA in Figure 24 indicating altitude may be a factor involved when the debris stream of nova WZ Sagittae causes the infestation.

Madagascar is known to be a mountainous Island and it was noted that the plague infestation occurs in villages at higher altitudes beginning in the month of June or July annually as shown in Figure 24. The south western terminus has a CAM date of July $20^{\text {th }}$ and a longitudinal location of $65 \mathrm{E}$. This terminus is known to deflect to the west 25 degrees [25]. The deflection causes the debris stream focal point to pass over Madagascar in late June or early July annually to cause the bubonic plague outbreaks in Madagascar shown in Figure 24 and south eastern Africa. This is an important find for SNIT because the CAM date and longitudinal location both agree with the theory that was mathematically derived using the north eastern terminus and right ascension of WZ Sagittae.

The third tine of Satan's fork of WZ Sagittae [25] as a red area

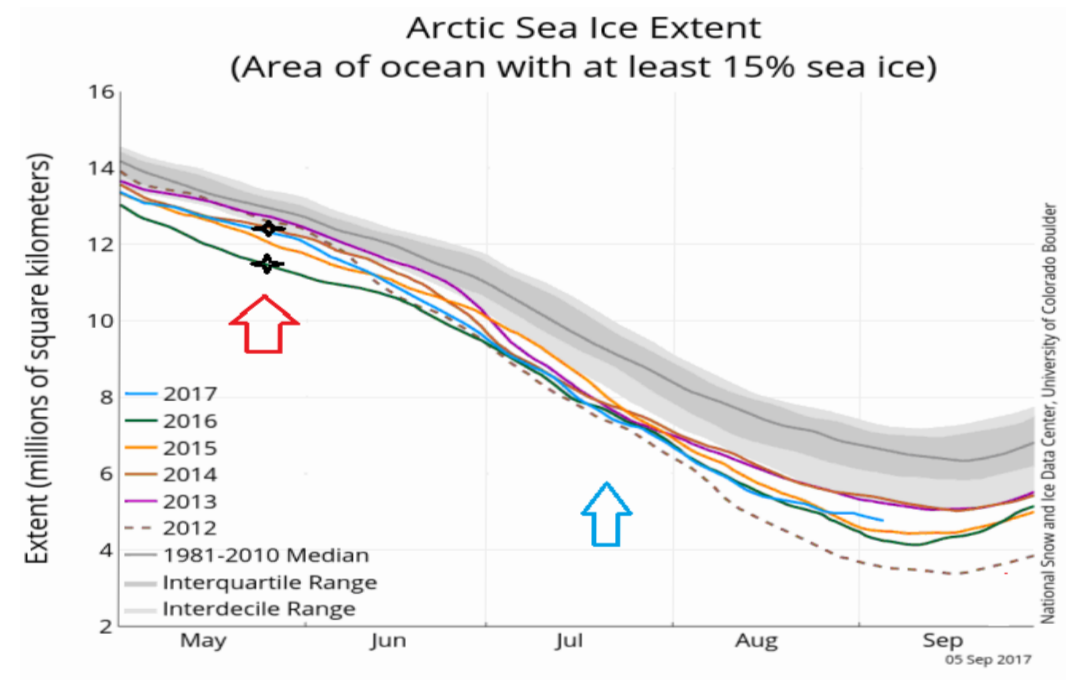

Figure 23a. Increased Sea Ice Areas North Pole SN 1006 and WZ Sagittae 2017 [33a]. 


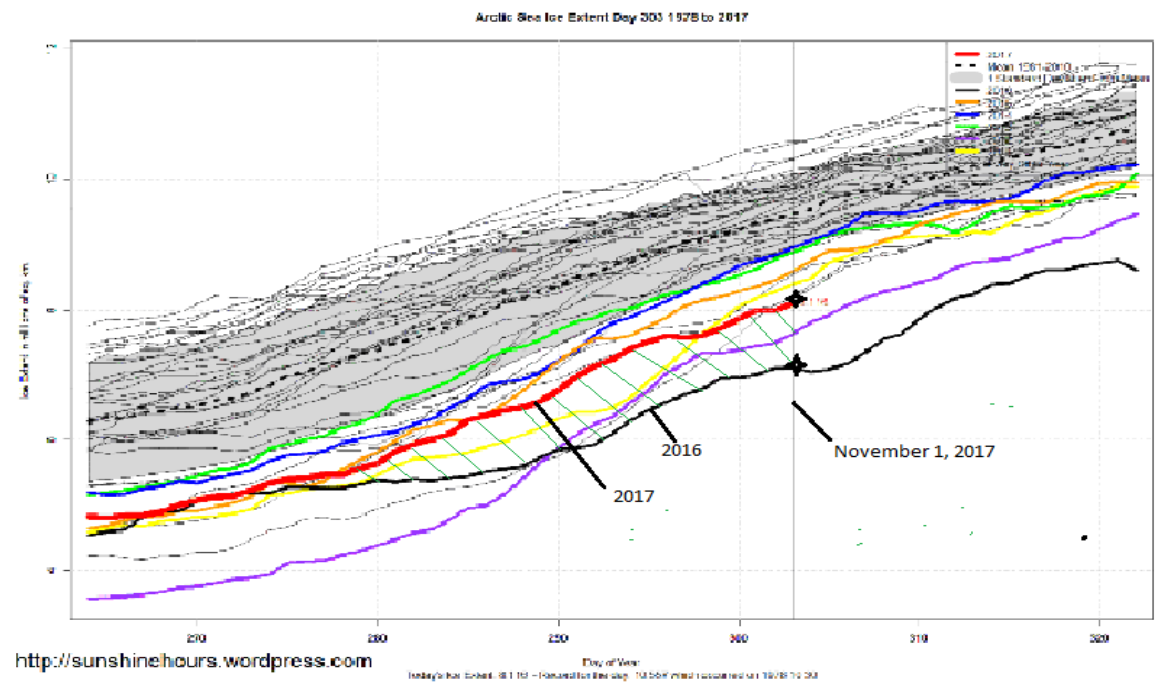

Figure 23b. Increased Sea Ice Areas North Pole SN 10062017 [33b].

A

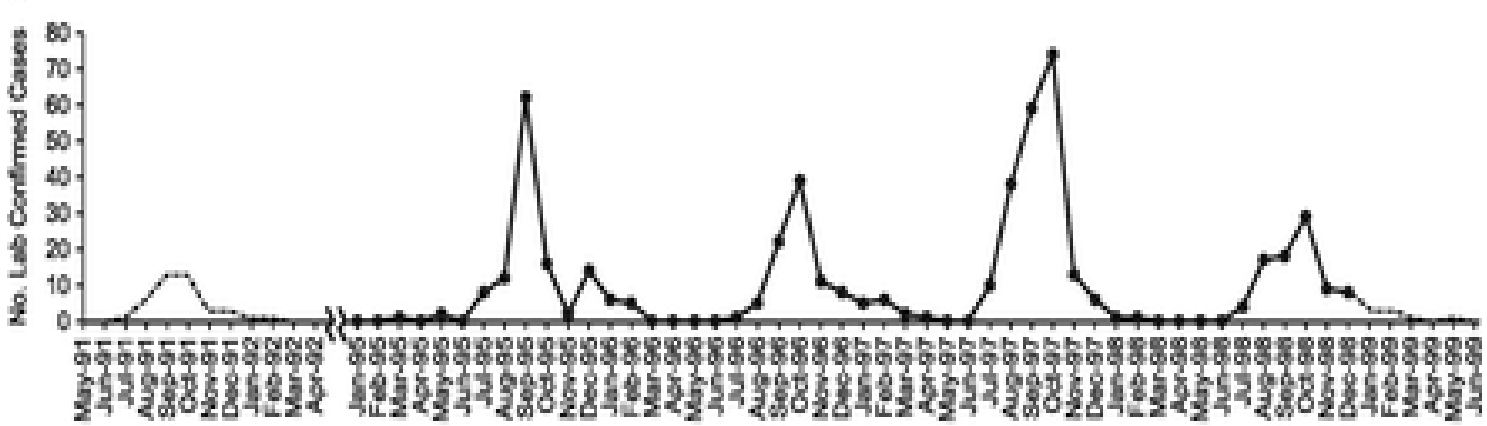

B

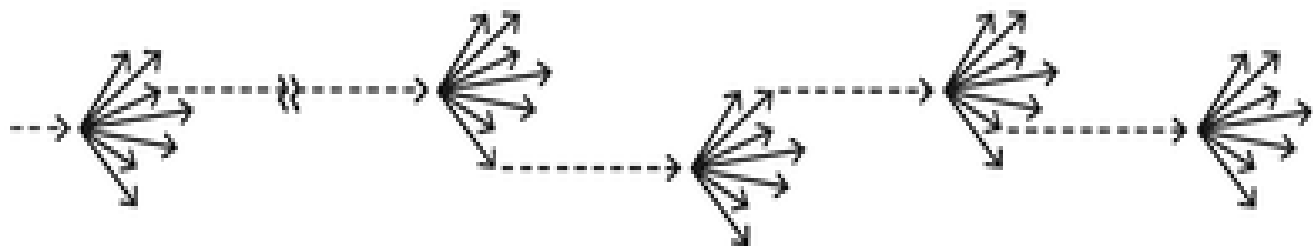

Figure 24. Madagascar Bubonic Plague Outbreaks 1991 to 1998 [35].

indicating an El Nino event touching Ecuador and northern Peru in South America also relates to plague at altitude in the Andes Mountains shown as red areas in Figure 25.

Since WZ Sagittae is a nova and a recurrent cataclysmic variable star, it stands to reason the larger than atom germ has more difficulty penetrating the atmosphere and as a results most infections of the plague occur at altitude. This fact has been successfully demonstrated for all three cases cited.

Since the third tine of the WZ Sagittae debris stream is associated with the eastern terminus of the nova, the beginning date of the plague outbreaks should be near January $20^{\text {th }}$ in Ecuador and northern Peru and occur annually.

\section{Conclusion}

The Monogem Ring Supernova event must be guarded against by the invention of a preventive device and not allowed to happen. If this event occurred today, civilization as we know could be destroyed in a northern part of a 180 degree land sector and millions would starve all over the world due to the lack of food production. Events similar in nature have happened in the past and any scientist can tell you an ice age will happen again if steps are not taken to prevent it.

The normal sequence of events for a supernova strike on our planet has a blush of heavy elements first, lighter elements of the debris stream impacting next and at a later time heavier elements reoccur in the debris stream. The examples stressed in this work are hydrogen, helium, and carbon (forming oil) and iron (with silicon forming red sands). These deposits occur at the longitudinal location of the densest particle point, the supernova's termini, and cause catastrophic change at these locations. India is experiencing the greatest threat to date and a large effort needs to be made to protect their population. Carbon particles from SN 1006 burning in the atmosphere and passing through humans will result in extreme epidemics for India, Russia, and the Mideast. The burning carbon particles from SN 1054 will produce similar results in the USA but to a lesser degree. 


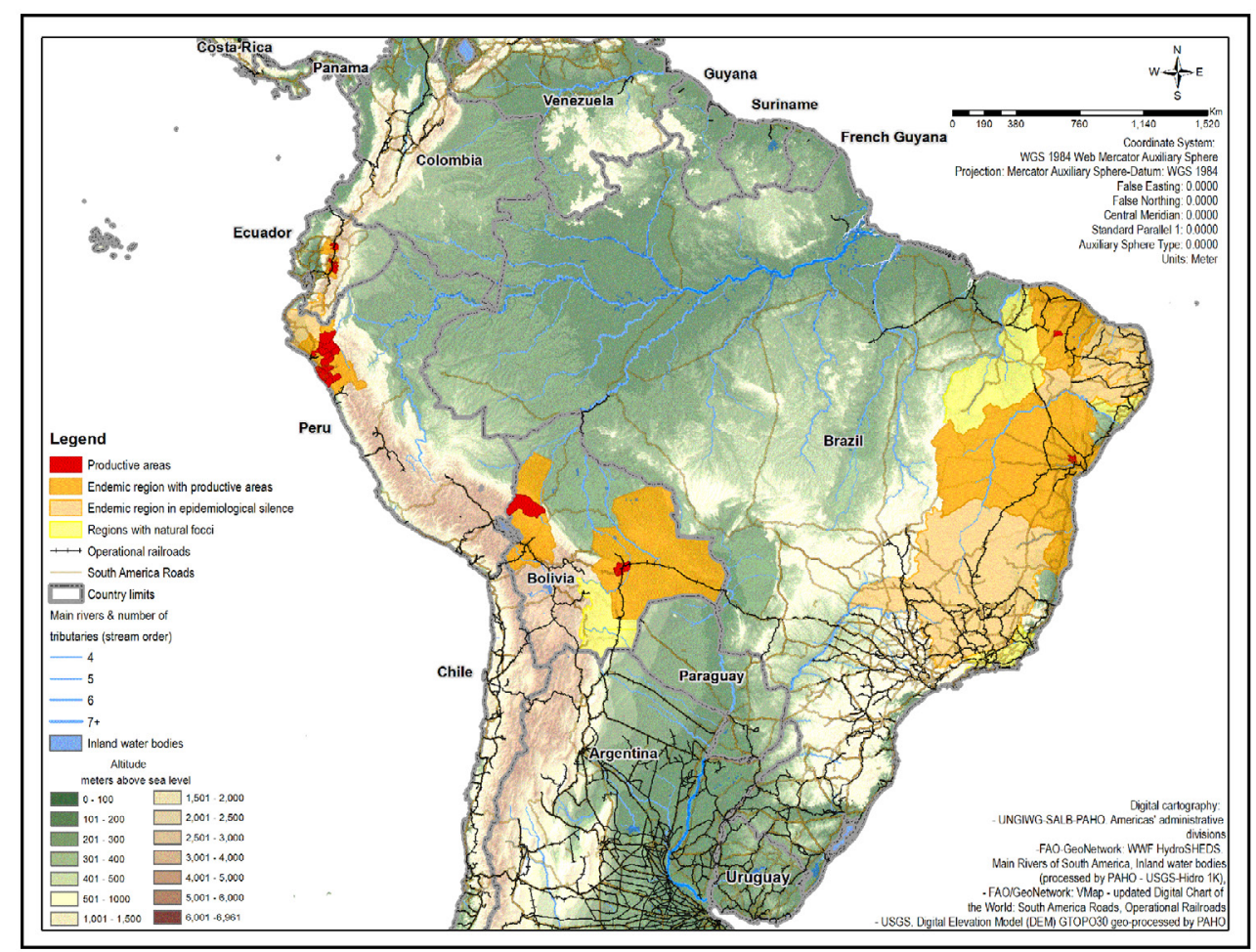

Figure 25. Red Areas Ecuador and Peru Bubonic Plague [36].

Supernova debris streams never end but the density of incoming particles will change. Continual passage of carbon particles through humans will cause cancer, the incurable disease.

The location and timing of the grouped lower average temperatures of Alaska produced by the changing characteristics of the debris stream of WZ Sagittae is sufficient proof of droughts on earth being produced by debris streams from exploding stars.

The future and past changing thermal conditions of our planet's climate can be predicted by a complete survey of supernova and nova explosions. The exploding stars the author has discussed could not possibly contain the complete list. Astronomers have been doing research for years that has appeared to be simply for the sake of research, but now the exploding stars have become very important to mankind. The Monogem Ring event would dwarf the effects of any asteroid collision and millions are spent tracking asteroids. The amount of work to be done in the SNIT area is enormous.

The understanding of termini locations and correlation of plague outbreaks, hotspots, melting ice, oil deposits, and red sands for numerous supernovas is the major part of the proof of the SNIT. It is easy to see that seeding the oceans with iron would reduce worldwide global warming, but what action should be taken to reduce the global cooling that follows the global warming phase of a supernova cycle? As usual, man contends with what is happening now, Global Warming, and does not consider the results of removing a substantial amount of $\mathrm{CO}_{2}$ from our atmosphere before the cooling phase of the supernova cycle begins. Another occurrence of the dark ages could result if too much $\mathrm{CO}_{2}$ is removed.

If the proposed model for global warming predicts past polar ice melts accurately, it can be trusted to specify the phenomenon currently producing the melts and to predict future global warming problems for mankind. SNIT has displayed this capability.

Theories involving the initiation of ice ages will change. The most famous theory on the subject is the Milankovitch cycles [32]. Since it has been proposed that ice age glaciations are caused by nearby exploding stars with high iron content, it is obvious as to why this phenomenon is so rare. The required condition to discontinue our last ice age, an interstellar meteor strike, is far less frequent than an impacting supernova debris stream an could be a true disaster if the strike's exit crater was on land during a warm period like today. A defense for this scenario needs to be created to protect the populations and nations of earth. This is by far the most difficult problem mankind will ever encounter.

The impact of SN GK Persei in nearly 80 years will be announced by a record breaking tornado outbreak in the USA.

The new concepts presented by this work for the scientific community are a meteor from an exploding star of large mass and traveling at a velocity capable of penetrating our planet and the moon in conjunction with an exit crater. There are many large craters on our planet that have not been formed by asteroid or comet collisions. There are people that know that very large lava plateaus like the Siberian Traps were not produced by lava seeping through cracks in the earth's mantle. The sooner mankind admits to the truth of these concepts that have been presented and deals with the implied threats, the sooner mankind will reach its destiny.

Specific melting and freezing locations of sea ice at different poles are predicted by the SNIT as a function of the north south motion of the debris stream termini. The $\mathrm{CO}_{2}$ theory of man 
made global warming cannot perform this feat. This fact proves that man made $\mathrm{CO}_{2}$ cannot be the reason our planet is getting warmer. In reality, the man made $\mathrm{CO}_{2}$ theory does not have a heat source of sufficient power to cause the observed warming.

Surely countries should join together in the suggested effort to protect mankind from a future ice age or incoming interstellar meteor.

Global Warming may be our friend and not our enemy because it occurs in local areas and the planet can continue to produce crops for the current population of mankind. The Little Ice Age and the Dark Ages have proved that this is not true for Global Cooling.

Since the tektite strata date correlates the interstellar meteor strike in Cambodia with the timing of the nano-diamond meteor from SN W50 that ended the Wisconsin glaciations, the obvious conclusion is that the chain of events caused by the earth piercing meteor from east to west are real. Dr. O'Keefe proposed tektites as moon debris and Dr. J. Kennet proposed the debris field in Figure 8 as a result of the nano-diamond meteor, both proposals were rejected by the scientific community. Dr. O'Keefe and Dr. J. Kennet are both correct. A very large number of cases of meteors passing through our solar system so fast that astronomers could not determine their orbits were debunked by the USA defense scientist saying the astronomers made mistakes in all the cases. The defense scientists also denied the astronomers further use of their satellite meteor tracking system. Is it possible that someone does not want us to know that large interstellar meteors are passing through our solar system at near light velocity?

Since the enemy that can destroy civilization as we know it comes from exploding stars, how stupid it is to expend our time an effort to conceive devices to kill our brothers and sisters.

\section{References}

1. https://en.wikipedia.org/wiki/Ice_core

2. http://en.wikipedia.org/wiki/Pulsar -- Significant Pulsars

3. http://iopscience.iop.org/article/10.1086/377682/fulltext/

4. http://www.blackiron.com/Projects/Shymanivske-Project/ default.aspx

5. http://www.steeltimesint.com/news/view/zambiadevelops-iron-ore-for-dri

6. https://en.wikipedia.org/wiki/Wisconsin_glaciation

7. https://en.wikipedia.org/wiki/Last_Glacial_Maximum

8. https://www.esciencecentral.org/journals/impact-of-climatechange-on-biodiversity-loss-and-extinction-of-endemicplants-of-arid-land-mountains-2332-2543.1000120. php?aid=23166

9. Parker AG, Eckersley L, Smith MM, et al. Holocene vegetation dynamics in the northeastern Rub' al-Khali desert, Arabian Peninsula: a pollen, phytolith and carbon isotope study. J Quaternary Scince. 2004;19:665-76.

10. http://www.giss.nasa.gov/research/briefs/gornitz_09/

11. Sokeland WP. Supernova, Nova Explosion's Space Weather: Correlated Megafauna Extinctions and Biosphere Mega-disturbances - Global Warming. Journal of Earth Science and Engineering. 136-53.

12. http://www.ncdc.noaa.gov/paleo/pubs/alley2000/
13. https://www.nrao.edu/pr/2013/w50/

14. https://www.ancient.eu/Fertile_Crescent/

15. https://en.wikipedia.org/wiki/Rub'_al_Khali

16. https://en.wikipedia.org/wiki/Right_ascension

17. http://alfin2300.blogspot.com/2011_01_01_archive.html

18. https://tribune.com.pk/story/1132448/pakistans-oil-gasdiscoveries-touch-record/

19. http://sustainability.colostate.edu/sites/sustainability. colostate.edu/files/pdfs/SustainabilityPosters/ Group1Project.pdf

20. http://www.dailymail.co.uk/sciencetech/article-3798411/ Climate-change-drove-early-humans-leave-Africa-fourwaves-beginning-100-000-years-ago.html

21. https://lion9104.wordpress. com $/ 2010 / 10 / 24 / \%$ E2\%80\%9Cdreamvacation $\% \mathrm{E} 2 \% 80 \% 9 \mathrm{D} /$

22. https://www.wunderground.com/cat6/historic-heat-wavesweeps-asia-middle-east-and-europe

23. Sokeland WP, Sagittae WZ, SN 1054, et al. Space weather global warming, Journal of Earth Science and Engineering. 2017.

24. http://models.weatherbell.com/temperature.php

25. http://www.earthsci.org/fossils/space/tektites/tektites. html\#Age_Paradox

26. http://www.sil.si.edu/smithsoniancontributions/ EarthSciences/pdf_hi/sces-0017.pdf

27. https://en.wikipedia.org/wiki/Mud_volcano

28. https://www.wired.com/2013/01/submarine-eruption-inthe-black-sea-off-georgia-not-likely/

29. https://en.wikipedia.org/wiki/Cambodia

30. https://en.wikipedia.org/wiki/Milankovitch_cycles

31. https://www.climate.gov/news-features/features/2016shatters-record-alaskas-warmest-year

32. A. http://jwcc.iwaponline.com/

B. https://sunshinehours.net/2017/10/31/sea-ice-extentglobal-antarctic-and-arctic-day-303-2017/

33. Sokeland WP, WZ Sagittae Space Weather- Global Warming. Journal of Earth Science and Engineering. 154-74.

34. http://mbio.asm.org/content/4/1/e00623-12.full

35. http://journals.plos.org/plosntds/article? $\mathrm{id}=10.1371 /$ journal.pntd.0002680

36. https://en.wikipedia.org/wiki/Babylon

37. https://en.wikipedia.org/wiki/Dilmun

\section{*Correspondence to:}

William P Sokeland

Retired Heat Transfer Expert

Spacecraft and Turbine Engines

Oakland City

Indiana 47660

USA

Tel: 812-304-9629

E-mail:wpsokeland@yahoo.com 